\title{
Capability-based governance patterns over the product life-cycle: an agent-based model
}

\author{
B. Vermeulen ${ }^{1,2}$ - A. Pyka ${ }^{2}$ J. A. La Poutré ${ }^{3,4}$. \\ A. G. de $\operatorname{Kok}^{1}$
}

Received: 15 December 2013 / Accepted: 16 November 2016 / Published online: 28 November 2016

(C) The Author(s) 2016. This article is published with open access at Springerlink.com

\begin{abstract}
In recent literature, there is disagreement over the temporal pattern of vertical governance of firms over the product life-cycle. We use a novel neo-Schumpeterian agent-based simulation model to investigate emerging patterns of vertical governance for different levels of imitability and substitutability of capabilities. We find that, in the mature phase of the product life-cycle, firms generally prefer vertical specialization. However, in the early phase, imitability and substitutability, in interplay, determine the governance form preferred. High imitability frustrates appropriation and thereby discourages integration for synergistic advantages. However, firms need not vertically specialize: under low substitutability, incompatibilities reduce the advantages of specialization. When both substitutability and imitability are low, firms can appropriate the value of their inventions and there is no combinatorial advantage of specialization, so firms predominantly integrate. If substitutability is high and imitability is low, the combinatorial advantage of specialization balances with the synergistic advantage of integration.
\end{abstract}

\footnotetext{
The first author gratefully acknowledges financial support of the Dutch science foundation NWO, Grant 458-03-112, and of the DACH research program Innovation Networks for Regional Development partly funded by the German science foundation DFG, Grant PY 70/8-1.
}

$\varangle$ B. Vermeulen

b.vermeulen@uni-hohenheim.de

1 School of Industrial Engineering, Eindhoven University of Technology, Eindhoven, The Netherlands

2 Institute of Economics, University of Hohenheim, Stuttgart, Germany

3 CWI - Centre for Mathematics and Computer Science, Amsterdam, The Netherlands

4 Department of Electrical Engineering, Mathematics and Computer Science, Delft University of Technology, Delft, The Netherlands 
Keywords Vertical governance $\cdot$ Capabilities $\cdot$ Imitability $\cdot$ Substitutability $\cdot$ Product life-cycle $\cdot$ Agent-based model

\section{Introduction}

Recent research is concerned with the temporal patterns in the vertical governance ${ }^{1}$ over capabilities $^{2}$ of firms over the product life-cycle (e.g. Jacobides and Winter 2005; Cacciatori and Jacobides 2005; Argyres and Bigelow 2010; Argyres and Zenger 2009). In the classical literature on the make-or-buy decision, the competitive conditions remain unchanged. However, whenever the market, technology, or competition changes, firms are likely to reconsider the vertical governance over capabilities they (do not) have. In literature, there is disagreement on whether being vertically integrated or rather vertically specialized is beneficial for competitive performance, particularly during the early phase of a product life-cycle when there is considerable turmoil on the product market. According to Afuah (2001), Jacobides and Winter (2005) and Fine (1998), vertical integration is preferred because this allows efficient research and development, facilitates horizontal differentiation and breaking away from existing technological paradigms, and enhances knowledge absorption. According to Harrigan (1985) and Balakrishnan and Wernerfelt (1986), vertical specialization is preferred because it allows flexible recombination with alternative complements provided by specialized entrants, thus prevents being locked in into a certain product design while reaping positive scale economies and benefits of component competition.

Arguably, the disparity in the vertical governance pattern over the product life-cycle relates to differences in characteristics of technological capabilities and the products produced. Whenever products are technologically complex with many intricately interacting components (e.g. first generations of computers), the first ones to be developed and produced have unique, integrated designs. Only over time, firms seek to commoditize products by modularization, outsourcing of component production to dedicated suppliers, etc. (Baldwin and Clark 2000). Whenever products are inherently modular or have separable production steps (e.g. apparel), firms are reluctant to vertically integrate even in the early stages of development. In any case, with the emergence of a dominant design, there is a tendency to modularize, vertically specialize, and outsource component production (cf. Baldwin and Clark 2000). That said, though, there are ample cases in which an industry persistently accommodates a mix of governance forms. Fine (1998) provides an elaborate discussion of the case of the personal computer. Although personal computers were initially integrated products, progressive modularization to reap positive economies of scale led to the formation of a vertically specialized consortium of Microsoft, Intel, and IBM. The emerging product design allowed consumers to combine components ('plug-and-play') and thus facilitated a swarm-in of specialized firms producing software, chips, peripheral hardware, etc.,

\footnotetext{
1 With 'governance' we refer to the legal vertical scope over capabilities of a firm. For a detailed introduction of 'vertical governance', we refer the reader to the seminal work of Williamson $(1981,1985)$.

2 For the remainder of this paper, we use 'capabilities' to refer to the set of knowledge and skills to develop and produce a particular product.
} 
thereby offering many options to consumers. Despite the dominance of the modular product design and the associated vertical specialization in the personal computer industry, Apple created a persistent niche of a vertically integrated design in which software and hardware are highly attuned, thus offering higher quality products, yet limiting the entry and competition at the component level.

In this paper, we take a capability-based perspective on governance decisions. Our contention is that differences in the temporal pattern in vertical governance forms chosen, and notably during the early phases of the life-cycle, are due to differences in substitutability and imitability of production capabilities (cf. Teece et al. 1997; Barney 1991). We study the patterns of vertical governance over the product lifecycle and how these patterns change with capability properties. ${ }^{3}$ We provide a novel neo-Schumpeterian agent-based simulation model to analyze the effects of these capability properties on the governance forms that evolutionary emerge. The agent-based model features a two-tier industry with component producers (suppliers) operating on the upstream tier, system producers (assemblers) operating on the downstream tier buying components and selling a final system to end-consumers, and firms that produce both. Firms search in a multi-dimensional space of capabilities (Gilbert et al. 2001, 2007), and combine system and component production capabilities (either fully in-house or by teaming up with a firm providing complementary capabilities) to produce products. ${ }^{4}$ We ensure that common stylized facts of the product life-cycle for homogeneous products (i.e. swarm-in/shake-out of firms, an alternating pattern of technological turmoil and convergence in technology, and profit erosion) are reproduced. We experimentally vary the imitability and substitutability of capabilities and study the evolutionary emerging governance pattern over the product life-cycle as dependent variable. The cost structure (economies of scale in production, switching costs, research costs) is the mediating variable.

We find that, in the mature phase of the product life-cycle, firms generally prefer vertical specialization. In the early phase, however, no single governance form dominates. High imitability frustrates appropriation and thereby integration for synergistic advantages. However, firms need not vertically specialize: under low substitutability, incompatibilities reduce the advantages of specialization. When both substitutability and imitability are low, firms can appropriate the value of their inventions and there is no combinatorial advantage of specialization, so firms predominantly integrate. If substitutability is high and imitability is low, the combinatorial advantage of specialization balances with the synergistic advantage of integration. Ultimately, we conclude that an integrated conceptual framework containing both imitability and substitutability is required to determine whether firms vertically specialize to be able

\footnotetext{
3 Although we acknowledge that different capabilities in one and the same industry may have different substitutability and imitability, we study the case that an industry has a certain capability 'regime' in the sense that all capabilities in the industry have the same level of imitability and substitutability.

4 Since there are 'firms' on both tiers of a supply chain and they all produce 'products', we say that 'suppliers' on the upstream tier produce 'components' which are then used by 'system producers'/'assemblers' to produce the final product ('system') then sold to the end-consumers. We use 'firm' and 'product' only when we refer to both upstream and downstream firms and products, or when additional information clarifies which one we mean. Furthermore, if we use 'product' in the general sense (so, the product made upstream or downstream), we use 'complement' to refer to the other product (so, downstream respectively upstream).
} 
to switch to alternative complements or rather vertically integrate to fine-tune system and components.

This paper is organized as follows. In Sect.2, we discuss literature on the product life-cycle and formulate hypotheses on how capability properties imitability and substitutability affect governance decisions in the different phases of the product lifecycle. In Sect. 3, we define our neo-Schumpeterian agent-based simulation model. In Sect. 4, we present, analyze, and interpret the simulation results. In Sect. 5, we briefly summarize our findings, draw conclusions, and discuss avenues for further research.

\section{Literature}

We discuss the literature on the product life-cycle, particularly characterizing the competitive challenges. We then elaborate on the (dis)advantages of the governance form in searching for high performing (combinations of) capabilities. Next, we discuss how the imitability and substitutability of capabilities mediate how governance affects search. Finally, we formulate hypotheses on the governance form in the different phases of the product life-cycle in general and for different levels of imitability and substitutability in particular.

\subsection{Product life-cycle}

Contingency models of the industry evolution (e.g. Levitt 1965; Wasson 1974; Utterback and Abernathy 1975) describe the pattern of interlocking evolution of demand, competitive activities, and technology research and development. The evolution of industries with homogeneous demand ${ }^{5}$ is expected to abide by the cycle of technological change (cf. Malerba 2006) of the alternating era of ferment after a breakthrough technology and era of incremental change following the emergence of a dominant design (Anderson and Tushman 1990; Tushman and Anderson 1986). In the era of ferment, entrepreneurs compete on different product-market propositions. In the era of incremental change, firms follow the dominant design and rival for consumers' demand by price competition through cost reduction, efficiency increases, and process innovation. With a further erosion of profit margins, firms seek to develop the next generation of products with, again, high profit margins. This radical breakthrough innovation triggers a new onset phase.

Various authors (e.g. Klepper 1997; Murmann and Frenken 2006) have stressed that the existing contingency models of industry evolution lack a vertical orientation, i.e. do not account for upstream industry conditions that affect the industry development. Recently, scholars engaged in describing the governance patterns over the product life-cycle (cf. Fine 1998; Jacobides and Winter 2005; Cacciatori and Jacobides 2005; Argyres and Bigelow 2010; Argyres and Zenger 2009). We follow these organizational economists in that both capability-based concerns and cost-based concerns and their

\footnotetext{
5 Under heterogeneous demand, firms may also pursue product differentiation. Under these circumstances, a segregated market may emerge with a 'dominant design' per niche rather than for the whole industry (cf. Bonaccorsi and Giuri 2000; Windrum and Birchenhall 1998; Malerba 2006).
} 
dynamic interplay determine the governance form. However, our explicit contention is that during the era of ferment, the emphasis is on R\&D such that governance decisions are dominated by capability-based concerns, while, during the era of incremental search, the emphasis is on manufacturing such that governance decisions are dominated by cost-based concerns. From organization ecological perspective (cf. Duysters 1995; Hannan and Freeman 1977) we know that also the type of firms evolves over the industry life-cycle. During the era of ferment, the population consists of many specialized entrepreneurs that compete on product performance and respond swiftly to opportunities, while, in the era of incremental change, the population consists of a few large manufacturing firms that exploit scale advantages of mass-production.

\subsection{Governance form and search}

In our simulation model, we adopt the knowledge-based perspective on product innovation (Gilbert et al. 2001, 2007) in which firms look for new capabilities or a new combination of capabilities to produce new, superior products. To realize competitive products, up- and downstream capabilities need to be attuned.

From a theoretical perspective, both governance forms have advantages in searching for a competitive combination of capabilities.

Firstly, there is a synergistic advantage of integration (Schilling 2000). Whenever a firm is vertically integrated, internal communication and cross-fertilization of knowledge is efficient. Input component and system technology can be closely attuned during development such that there is high internal compatibility (cf. Kogut and Zander 1992; Afuah 2001). An additional advantage is that integration excludes rivals from using the same input or system and ensures that the generated value is appropriated by its (integrated) inventor.

Secondly, there is a combinatorial advantage of specialization. Whenever firms are vertically specialized in a modular design, they can link up with alternative complement providers without having to engage in time consuming or costly redesign. For instance, a system producer can switch to an alternative (vertically specialized) input supplier to realize a new combination of capabilities (cf. Schilling and Steensma 2001; Dyer and Singh 1998). In case there are many suppliers that search independently for capabilities, system producers can consider more combinations than when vertically integrated. Furthermore, suppliers may trade with or be approached by more than one assembler, thus increasing their chances of sales. Vertical specialization thus allows decentralized search of many combinations.

So, vertical integration allows attuning for high performance plus appropriation of generated value, while vertical specialization allows recombination with components becoming available due to decentralized search. Note that vertical integration need not be a merger of two firms; a firm can vertically integrate forward or backward by either buying or developing the production capabilities needed.

\subsection{Properties of the capability regime}

A firm has a competitive advantage of owning a particular capability if this capability is valuable and rare, and hard to imitate and substitute (Barney 1991). In this study, 
we focus on imitability and substitutability. Imitability refers to the extent of efforts (costs, dedicated time, or other resources) needed to imitate capabilities. Substitutability refers to the extent to which swapping one capability for another is likely to affect overall performance (conditioned on values of both capabilities). Here, we formulate hypotheses on why firms would vertically specialize or integrate for different levels of substitutability and imitability.

Firstly, if substitutability is high, capabilities are modular, and swapping one component (system) for another component (system) capability is likely to yield few compatibility issues. The more substitutable (more modular/less complex) capabilities, the more eager firms are to specialize (cf. Argyres and Bigelow 2006; Sanchez and Mahoney 1996). Alternatively, if component and system capabilities are complexly interwoven or finely attuned, swapping one for an arbitrary other capability is likely to lead to compatibility problems and thereby deter overall performance. In this case, vertical integration allows attuning upstream and downstream capabilities to arrive at an integrated, competitive product, while specialization and relying on external capabilities is likely to yield products whose performance is low due to incompatibilities. So, with a decrease in substitutability (increase in complexity), the combinatorial advantage of specialization decreases and the synergistic advantage of integration increases. Note that, due to these incompatibilities, integration as exclusion instrument is less important. The lower substitutability, the less valuable combinatorial search, and the less likely firms are to pursue vertical specialization (the more likely firms are to pursue integrated search). We expect this effect to become stronger if imitability drops, because appropriability increases for integrated firms.

Secondly, if imitability is high, the synergistic advantage of being integrated reduces. After all, if capabilities can be imitated relatively easily and relatively cheaply, the additional performance achieved by tight vertical governance vanishes with the swiftly followed imitation. Also the combinatorial advantage of being specialized reduces as (integrated) firms can quickly imitate a high performing combination found by other firms. Conclusively, if imitability is high, both advantages are relatively weak. However, by specializing, firms still enjoy decentralized search and consider more combinations than when fully integrated. Alternatively, if imitability is low, integration is an effective exclusion and appropriation instrument, whereas specialization allows competitors to access the same (possibly superior) upstream capabilities. Note that exclusion is less of a reason to integrate if those capabilities are of limited value for competitors. So, the value of arbitrary complementary capabilities drops whenever the substitutability drops. A system (component) producer does not need to exclude competing system (component) producers from accessing the same component (system) producer as they are likely to encounter compatibility issues anyhow.

Table 1 contains the hypotheses on the governance form sought under different levels of imitability and substitutability respectively as inferred above. In the ondiagonal cells, there is consensus, while, in the off-diagonal cells, there is ambiguity due to conflicting implications. 
Table 1 Governance forms as predicted by imitability and substitutability

\begin{tabular}{|c|c|c|}
\hline & \multicolumn{2}{|l|}{ Substitutability } \\
\hline & Low & High \\
\hline \multicolumn{3}{|c|}{ Imitability } \\
\hline \multirow[t]{2}{*}{ Low } & $\begin{array}{l}\text { H1: Integration for } \\
\text { exclusion/appropriation }\end{array}$ & $\begin{array}{l}\text { H1: Integration for } \\
\text { exclusion/appropriation versus } \\
\text { specialization to link w. top capabilities }\end{array}$ \\
\hline & $\begin{array}{l}\text { H2: Integration for attuning, } \\
\text { specialization suffers incompatibilities }\end{array}$ & $\begin{array}{l}\text { H2: Specialization for decentralized } \\
\text { search }\end{array}$ \\
\hline High & $\begin{array}{l}\text { H1: Specialization for decentralized } \\
\text { search } \\
\text { H2: Integration for attuning, } \\
\text { specialization suffers incompatibilities }\end{array}$ & $\begin{array}{l}\text { H1\&2: Specialization for decentralized } \\
\text { search }\end{array}$ \\
\hline
\end{tabular}

There is ambiguity on the governance form in the off-diagonal cells. In the era of incremental change

\subsection{Governance in different eras}

Recent research is concerned with the temporal patterns in the vertical scope of firms over the product life-cycle (e.g. Fine 1998; Jacobides and Winter 2005; Cacciatori and Jacobides 2005; Argyres and Bigelow 2010; Argyres and Zenger 2009). According to the cycle of technological change (Anderson and Tushman 1990; Tushman and Anderson 1986), the industry alternates between the eras of ferment and incremental change, punctuated by the emerge of a dominant design and a radical breakthrough. In each of these eras, the market, competitive and technological conditions differ, and so are the concerns in deciding on a governance form. Table 1 needs further specification for each of the two eras.

\subsubsection{Era offerment}

In the era of ferment, i.e.in the early phase of the PLC just after the radical breakthrough, the emphasis in firm activity is on research and development of new products. Entrants and incumbents frequently discover new component and assembly propositions and frequently bring new products to the market. So, during this era, there is a high risk that technological change proves in-house capabilities inferior. In that case, firms have to link up with (by switching to another supplier) or acquire superior capabilities (by imitation or absorption). This high risk of obsolescence and need for flexibility calls for vertical specialization (cf. Harrigan 1985; Balakrishnan and Wernerfelt 1986; Schilling and Steensma 2001; Afuah 2000). So, each firm thus faces a-what we call — 'high stakes/high gains' governance dilemma. A firm has to choose between, firstly, vertical integration to synergistically attune component and assembly at the risk of obsolescence, or, secondly, vertical specialization to enable flexible recombinatorial search but suffer incompatibilities. As there often is ambiguity, firms cannot always choose between becoming an 'opportunistic specialist-combiner' or a 'synergistic integrated developer'. 
If substitutability is high, flexible recombination is relatively valuable. If substitutability is low, the probability that a complement at the market yields a high performing product is low. Under low imitability, firms can effectively appropriate market value, so integration to reach a high performance is more valuable. The propensity to vertically integrate decreases with imitability.

\subsubsection{Era of incremental change}

In the era of incremental change, i.e. in the growth and mature phases of the PLC just after the emergence of the dominant design, firms face relatively stationary demand on the medium-long term and focus on large scale production. Technological changes are rare, such that firm may have dedicated manufacturing facilities. Consequently, firms pick the governance form primarily based on production and transaction costs. Firms outsource production if there are positive economies of scale in production in an upstream sector (cf. Stigler 1951), if there are diseconomies of scope (Prahalad and Hamel 1990), or positive economies of specialization (cf. Smith 2003). In general, transaction costs and diseconomies of scope mediate the appeal of specialization and integration in obvious directions: e.g. existence of positive economies of scale in the upstream sector promotes vertical specialization.

Given that technological change is infrequent, firms do not need to imitate or substitute capabilities. As such, the effect of regime properties is limited.

\section{Neo-Schumpeterian model}

In this section, we provide the specifications of our neo-Schumpeterian agent-based model. Section 3.1 contains a brief overview of the basic ideas behind the simulation model. In Sect.3.2, we explain the functional design of the simulation model. In the remaining subsections, we discuss the actual operational implementation.

\subsection{Overview}

Here we briefly discuss the basic ideas underlying the functional design of and the operationalizations in the simulation model, notably (i) that we seek to reproduce stylized facts of the product life-cycle, (ii) how our model extends the classical PLC, (iii) that product renewal through capability and product search interlocks with diffusion-substitution in consumer demand, (iv) how we seek to 'evolutionary train' the governance strategy, and (v) the experimental setup to investigate the effects of capability regime properties on emerging governance patterns.

To study the emerging vertical governance pattern over the product life-cycle, we specify a neo-Schumpeterian model that reproduces the classical PLC in which the industry alternates between two distinct phases of competition, separated by the emergence of a dominant design and a radical breakthrough (Utterback and Abernathy 1975; Anderson and Tushman 1990). In the early phase (era of ferment), the firm population consists of 'entrepreneurial' firms that focus on product innovation and run flexible job shops. In the mature phase (era of incremental change), the firm population 
Fig. 1 Graphical illustration of the industry structure. Here, one supplier provides components to two system assemblers, and there is one integrated firm

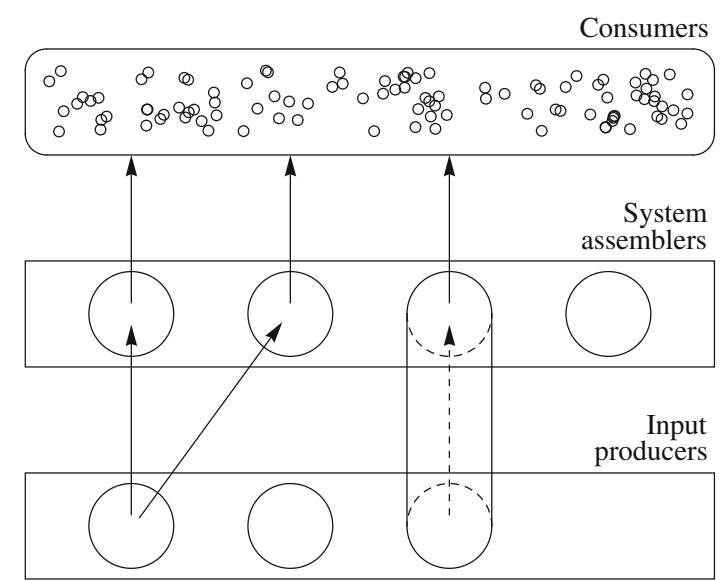

consists of 'mass-manufacturing' firms that operate dedicated, large scale production equipment. Typical simulation results (see Sect.4) of our neo-Schumpeterian model feature distinct eras of ferment and of incremental change and reproduce the stylized facts of swarm-in/shake-out, turbulence/convergence in product technology, and profit erosion.

However, in our model, we move away from the traditional single tier models of an industry and rather have a two-tier industry. At the downstream tier, system producers/assemblers produce systems to be sold to consumers. At the upstream tier, firms produce components that are input into the system that is made downstream. A vertically integrated firm produces the system and the input component. A vertically specialized system producer buys components from a vertically specialized component producer. Figure 1 illustrates the industry structure.

In any neo-Schumpeterian agent-based model, firms compete for consumer demand through product innovation and price setting. Following the SKIN model (see e.g. Gilbert et al. 2001, 2007), firms look for new capabilities or a new combination of capabilities to produce new, superior products. In Sect. 3.4, we describe how firms with different governance forms search an upstream and a downstream capability landscape for new capabilities and combine these capabilities to make products. A vertically integrated firm explores combinations of the system and component capabilities that it owns, fully in-house. A vertically specialized firm explores combinations of its own capabilities with complementary capabilities owned by potential partners. The capabilities are combined to produce products that are then launched, dynamically priced, and ultimately withdrawn from the market following the heuristics described in Sect. 3.5. In Sect. 3.6, we describe how consumers buy products based on price and performance, their individual willingness-to-buy, and word-of-mouth.

Given that firms incur costs for searching, producing, and changing production, only firms that follow strategies that efficiently generate superior products will survive competition in the long run. The firms in our model follow three different strategies: the business strategy (whether and when to be mass-manufacturer or entrepreneur), the product search strategy (when to explore or rather imitate, when to conduct radical 


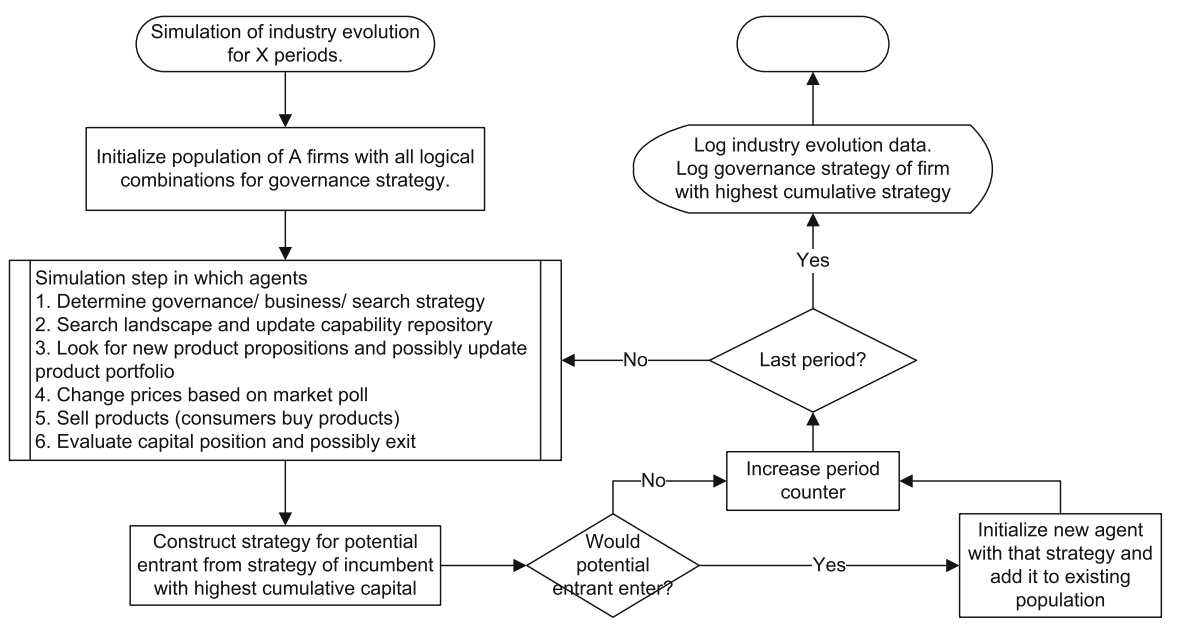

Fig. 2 Flowchart of industry evolution with evolutionary learning of strategy

search), and the vertical governance strategy (when to vertically integrate or specialize). In Sect.3.3, we describe the operationalization of these strategies in detail. The strategies of superior firms are imitated by entrants to establish 'evolutionary learning' (at the population level) of these strategies. A flowchart of this industry evolution with evolutionary learning of strategies is given in Fig. 2.

In the present work, firms learn two strategy variables ${ }^{6}$ : the governance form (integrated/specialized) before and after the emergence of the dominance design.

The industry level parameters (production costs, diffusion rate, periodic costs, etc.) are treated as mediating variables. The agents' decision variables (decision thresholds are discussed later) are taken constant and equal for all agents. By homogenizing firms in this way, evolution trains just the governance strategy. The values chosen for mediating variables and strategy decisions parameters are given in "Appendix 1". In Sect. 4.1.2, we discuss our parameter choices in detail.

\subsection{Functional design}

Our neo-Schumpeterian agent-based model is a discrete periodic simulation model. In each period, there are four consecutive stages of activities: a sales round, a round of strategic activities (in which firms may change the business model and/or their governance form), a round of operational capability and product search, and an entry and exit round.

\footnotetext{
6 In extensive experimentation with this model, several other strategy variables (e.g. the thresholds in the business strategy defining when firms switch from being an entrepreneur to being a mass-manufacturer, also the thresholds in the product search strategy defining when firms imitate rather than explore, etc.) were endogenously trained. However, there was only slow convergence in these strategies and the simulation results displayed substantial noise due to overparameterization.
} 
Firstly, there is a sales round in which (i) firms select products they will produce and the prices at which they will be sold, and (ii) consumers share experiences and determine what to buy. As described in Sect.3.5, firms launch new products by giving away promotional units and thus start diffusion-substitution. Moreover, firms remove products that are not consumed anymore or because they are old-fashioned (products of the newest-but-two generation are phased out). Firms set prices of currently produced products by conducting a poll among consumers. As described in Sect. 3.6, consumers consume part of their products, and-if in need of a new unit of product-consult a panel of other consumers (which thus operationalizes word-of-mouth) on which product to buy. Once consumers are aware of the existence of a new generation of products, they become increasingly eager to buy these products. Consumers pick a particular product based on the recommendations of consumers in a panel.

Secondly, as described in Sect.3.3, firms follow their business, governance, and capability and product search strategies. The capability search strategy is 'exploration', 'imitation', or 'radical search' depending on market concentration, profit margin, and the gap in performance between own and competing products. If a firm is in imitation mode (step-by-step development of the capability of a competitor) or conducting radical search, the firm will finish that before following business or governance strategic actions. If a firm is in exploratory mode, the firm consults its business strategy and may set the business model to 'entrepreneur' or 'mass-manufacturer' depending on the market share of the product design. If a firm switches from one to another business strategy, it will also immediately vertically integrate or outsource in line with the governance strategy of that new business model.

Thirdly, as described in Sect.3.4, firms also conduct operational search for new capabilities on a capability landscape. The capabilities found are then combined into new products, either in-house for integrated firms or with another firm upstream or downstream for vertically specialized firms. A vertically specialized firm will also consider all new combinations if a complement producer discovers a new capability. A product thus developed is eligible for production and market entry if (i) the product portfolio does not already contain it, the portfolio is not full or the product's performance exceeds that of another product currently in the portfolio that it can replace, (ii) an estimate of the willingness-to-pay exceeds the production costs, and (iii) it is the first of a new generation or its performance exceeds that of the current top product on the market.

Fourthly, as described in Sect. 3.7, at the end of each period, firms that are bankrupt do exit (unless it is the last firm in the industry). Moreover, there is a firm waiting outside the industry which decides whether or not to enter.

\subsection{Strategies}

Each firm follows three strategies: a business strategy, a capability search strategy, and a vertical governance strategy. Following Anderson and Tushman (1990), we have firms change their business model upon the technological punctuations (emergence of dominant design, discovery of a radical breakthrough). Operationally, each agent has its own preferred governance form with either one of the business models. The 
business strategy, capability landscape search strategy, and the vertical governance are only reconsidered whenever the firm is engaged in exploration. Whenever the firm is engaged in imitation, differentiation, or radical search, the firm first finishes that search operation. We now describe these three strategies in detail.

\subsubsection{Business strategy}

We distinguish two types of agents: entrepreneurs and mass-manufacturers. An entrepreneur is focused on technological exploration and runs a job shop with versatile production facilities. Production switching is relatively cheap, but the fixed unit costs for production are high. A mass-manufacturer is focused on large scale production and runs a dedicated mass-production facility. Production switching is expensive, but the fixed unit cost for production are low.

Following Utterback and Abernathy (1975), Anderson and Tushman (1990) and Klepper (1996), we assume that during the early phase of the product life-cycle, the firms primarily follow an entrepreneurial strategy, while as soon as a dominant design emerges, the firms switch to a mass-manufacturing strategy. Operationally, the firm agents switch based on the design dominance metric $\hat{H}$ (defined in Sect.3.7), which simply quantifies how many consumers of the total consume a particular product. If $\hat{H}>H_{0}$, we say a particular design is dominant. Given that $\hat{H}$ is volatile and may hence cross $H_{0}$ repeatedly, we assume that there is a margin $0<m \ll 1$ and that only if $\hat{H}$ exceeds $H_{0}+m$, firms become manufacturers, and if $\hat{H}<H_{0}-m$, firms become entrepreneurs.

Firms can produce multiple generations of products. However, we assume that firms are entrepreneurial in the era of ferment of a new generation and (at the same time) mass-producing in the era of incremental search in the old generation. As soon as the new generation of products is phased-in in mass-production, the old generation of products-if still produced-is discontinued. Moreover, we assume that, as soon as a firm engages in exploration in a new generation of capabilities, the firm will pick the governance form that is beneficial for the entrepreneurial activities.

\subsubsection{Capability search strategy}

Firms have a capability search strategy that prescribes whether to (i) explore capabilities to produce a product with a higher performance, (ii) imitate capabilities to make a top product, or (iii) develop capabilities needed to produce a product of the next generation. In a homogenous product market, as we study in this paper, firms do not have a way to differentiate their product for a niche market.

The first consideration in what search heuristic to follow is that the firm (here: system assembler or integrated firm) continues exploration if the industry is premature, i.e. whenever there is no competing product or the performance of the best product is low. In a premature industry, firms continue searching for a product that is good enough to ultimately capture a large share of the market. If a competitor's top product has performance that exceeds the performance of a focal firm by far, that focal firm starts imitating the capabilities needed to produce that top product. A supplier follows the same rationale but then for the component. In case the firm is an entrepreneur 
(manufacturer), and if the performance of another product is $\geq 5 \%$ ( $\geq 15 \%$, which is higher because of higher switching costs) higher than the performance of his own product, the entrepreneur (manufacturer) will engage in imitation.

If the industry is mature but the competing top product is not good enough for imitation, the firm (here: assembler, supplier, or integrated firm) considers radical search. The firm will engage in radical search if one of three conditions holds. Firstly, the firm is a 'laggard', which we operationally define as that the firm is not yet active in a new generation of product technology while more than half of the consumers is already buying products of a new(er) generation. Secondly, the profitability of the current top performing product of the generation produced by the focal firm is negative. Thirdly, the smoothened profit margin is lower than a particular threshold (we picked 0.05 , i.e. if the profit margin drops below 5\%) and while the smoothened design dominance is higher than a particular threshold (we picked 0.80, i.e. one product technology is consumed by more than $80 \%$ of the consumers already). The design considerations for this third option are that if a certain technology is already dominant and the profit is low, there are insufficient opportunities in this industry. In that case, a firm will rather try to discover a new generation of products with more opportunities. If these conditions do not hold (so there are enough opportunities, there still is a sufficiently high profit margin, and the own performance is relatively high), then the firm continues local exploration.

The procedure that firms follow to determine their search strategy is depicted in the flowchart in Fig. 3.

\subsubsection{Vertical governance strategy}

Whenever a firm is engaged in exploratory search (so, not imitating or engaged in radical search), the firm changes its vertical governance according to the following simple heuristics. If an assembler does not find a supplier, or a supplier does not find an assembler, it will vertically integrate. So, this is not a merger of equals, but is the acquisition and in-house development of production capabilities.

In any other case, the firm picks the governance form related to the business model. In the era of ferment, i.e. prior to the emergence of the dominant design, the focal firm is entrepreneurial and picks the governance form for that business model. Similarly, after the emergence of the dominant design, the focal firm is a mass-manufacturer and picks the governance form for the era of incremental change. These two governance form specifications are the only two variables that are endogenously trained. As explained before, we limited the number of strategy variables trained to overcome slow convergence and noise in simulation results.

Whenever an integrated firm vertically specializes, it specializes in the tier in which it has the highest performing capability. Whenever an integrated firm becomes an assembler, this assembler links up with an existing supplier if this supplier provides the currently used or an even better component, but otherwise spins off its component capabilities to a newly established supplier with whom it then links. Similarly, whenever an integrated firm becomes a supplier and does not find an assembler with whom it can make the same product or a product with higher performance, this firm spins off its system production facilities to a newly established assembler with whom it then 


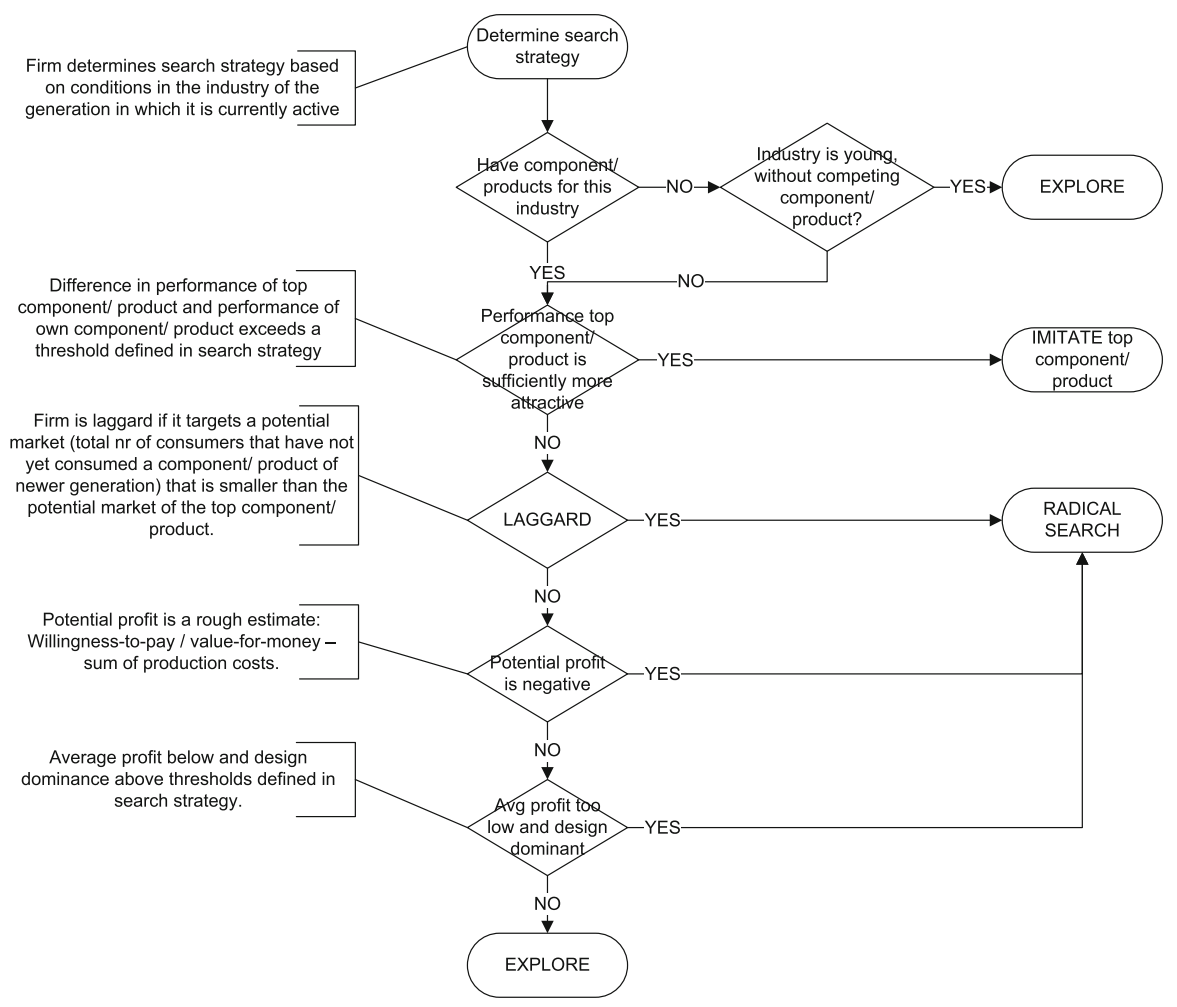

Fig. 3 The search strategy determines when to explore freely, imitate the top product/component/assembly or to engage in radical research to unlock the next generation of capabilities

links. From that moment onward both specialized firms follow their own (autonomous) heuristics that further improve their respective performances. The outsourcing agent considers switching to another supplier already the next period.

Upon integration, the firm acquires the complementary capabilities of its current production chain partner(s) and continues to produce the products, but now fully inhouse.

Note that while there is a threshold triggering a governance decision, firms need not change their governance form, so firms may remain vertically integrated or specialized over the whole product life-cycle.

The costs of integration and outsourcing are discussed in Sect. 3.8.

\subsection{Capability and product search}

Following the SKIN model (Gilbert et al. 2001; Pyka et al. 2009), firms conduct a twostage search. In the first stage, firms search on the capability landscape for new viable capabilities. In the second stage, firms recombine readily discovered component and system capabilities into product propositions, whereby integrated firms do so exclu- 
Fig. 4 Graphical illustration of the two capability dimension landscapes consisting of 'reels' of abilities/skills/techniques

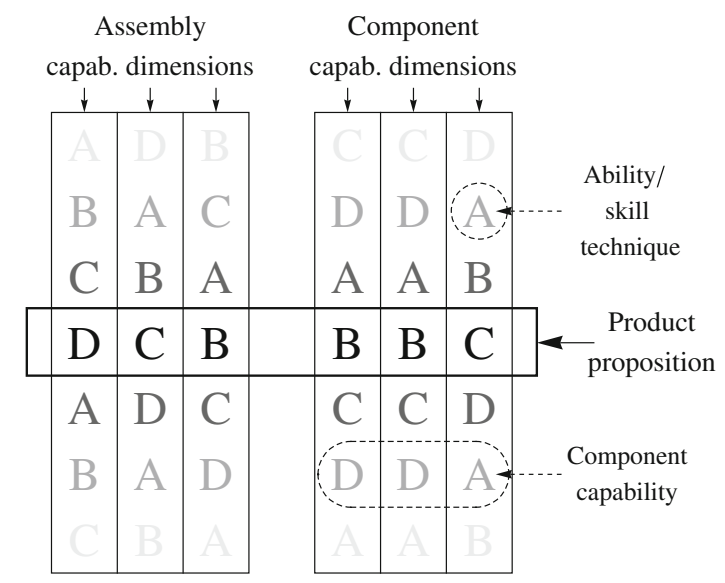

sively in-house, while vertically specialized firms collaborate with firms providing complementary capabilities. We now discuss both search stages.

\subsubsection{Landscape search for capabilities}

In the first stage, firms search on the capability landscape for capabilities. There are two capability landscapes (for each generation of products): one for system capabilities and one for component capabilities. We encode a capability as an alphabetic string of length $N$ capability dimensions, each with $D$ options. We take a capability to be a mix of techniques, capital goods, and skills/abilities to produce a certain output product. As soon as a focal firm finds a capability that is a local optimum in terms of performance and that is new to this firm, the firm adds it to its capability repository. We use the metaphor of the reels in a gambling slot machine (see Fig. 4): there are $N$ reels (capability dimensions) with $D$ pictures (specific skills/abilities/techniques/resources). At each tier, the firm is looking for capabilities in the space of size $D^{N}$ possible capabilities.

With regard to the performance of capabilities, we follow the island-sea landscape of Fagiolo and Dosi (2003). The 'sea' is formed by a big majority of the capabilities (each a unique combination of abilities, techniques, skills, etc.) that has a zero performance (i.e. technologically infeasible). The few capabilities that have non-zero performance are the randomly scattered 'islands'. The sea has to be 'sailed' to reach the islands. During generation of the capability landscape, we randomly select $C$ combinations that are feasible (so we have $C$ islands) and have a non-zero performance, and set the remaining $D^{N}-C$ capabilities to have a performance of zero. ${ }^{7}$ From innovation size distribution studies (e.g. Silverberg and Verspagen 2003), we infer that combinations

\footnotetext{
7 At first, we drew a performance value for each of the $D^{N}$ combinations. We found that the capabilities with very low performance were used only very rarely and only very briefly (until replaced by capabilities with higher performance). So, the effect of the capabilities with very low performance was limited. Truncating the very low performance values of the $D^{N}-C$ capabilities to zero, and thereby adopting the island-sea landscape, we shortened the computation time dramatically. Switching to an island-sea structure of the
} 


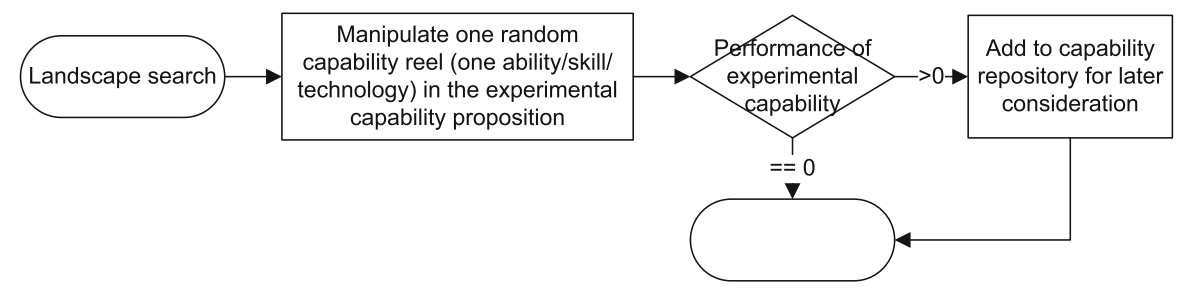

Fig. 5 Flowchart of operational landscape search in which the experimental capability is manipulated to find new feasible capabilities by trial-and-error

that are feasible have a certain performance distribution. We assume that, of the $C$ feasible capabilities, capability $i$ has a performance $q$ equal to $e^{-\alpha u^{\beta}} \in[0,1]$ where $u \sim U[0,1]$ is a uniform random variable. We tune this distribution with parameters $\alpha \geq 0$ and $\beta \geq 0$ to ensure that a large share of the capabilities has low performance, while a small share of the capabilities has high performance (cf. Silverberg and Verspagen 2003).

During exploration, the focal firm searches this landscape by changing one ability at a time of its experimental capability proposition, i.e. by turning one capability reel in Fig. 4 up or down one step at a time. If a capability is technologically feasible, i.e. has a performance higher than zero, it is added to the capability repository and is considered during the first stage of combinatorial product search (which is described in detail below). The process of capability landscape search is depicted in the flowchart in Fig. 5. We assume that firms have fixed search costs.

\subsubsection{Combinatorial search for product proposition}

By the operational search on the capability landscape, a firm discovers production capabilities that are added to its 'repository'. Firms subsequently combine a system and a component production capability into a 'product proposition'. Whenever an integrated firm discovers a new capability, it considers all combinations of this new capability with the complementary capabilities of the same generation currently in its repository. Whenever an assembler discovers a new system capability, it considers all new combinations with capabilities of suppliers by enumeration. Whenever a supplier discovers a new component capability, assemblers contact the supplier to evaluate all new combinations. This procedure is depicted in the flowchart in Fig. 6.

Firms start production (of their component or system, or the whole product) if the formed product proposition has a performance that is competitive with products already on the market. We assume that if either one of the capabilities is infeasible or produces a poorly performing component or system, the product will have a low performance. The performance of a product is high only if both the component and the system capability are technologically feasible and they are compatible.

Footnote 7 continued

capability landscape goes at the expense of having to add an additional parameter $C$ for the number of islands. 


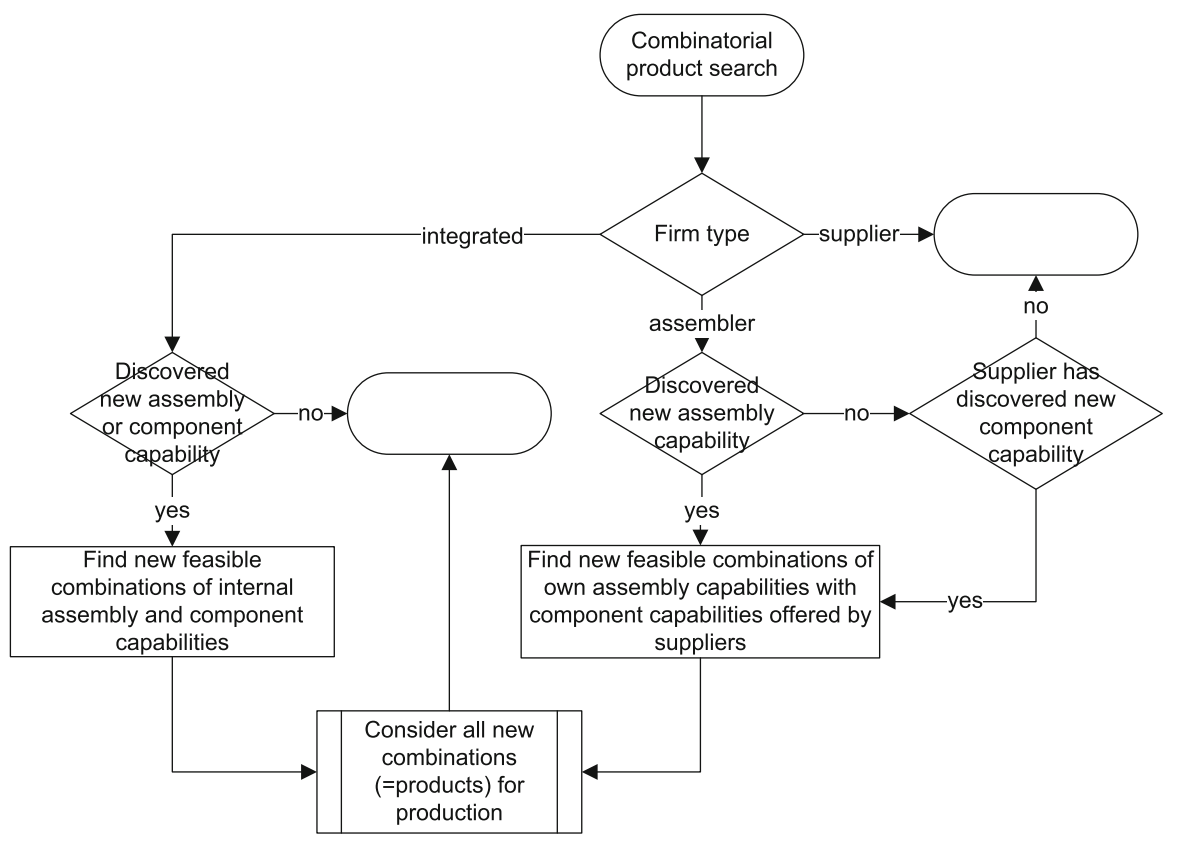

Fig. 6 Flowchart of combinatorial search for products by combining capabilities already discovered

To operationalize this interaction, we take the multiplication of the performances ${ }^{8}$ and the compatibility. The skewed nature of the total performance due to the multiplications is corrected by taking the third root. We thus get the following expression for the overall performance $q$ of a product:

$$
q=g+\sqrt[3]{q_{i}^{S} q_{j}^{I} c_{i j}}
$$

Hereby, $q_{i}^{S}\left(q_{j}^{C}\right)$ is the performance of the system $i$ (component $j$ ) in $[0,1], g$ is the generation of both component and system (which is described later when discussing radical search), and $c_{i j}$ is the compatibility $j$ and system $i$.

\subsubsection{Compatibility and experimental variable substitutability}

Following the landscape metaphor for capabilities, the compatibility $c_{i j}$ of the component and the system relates inversely to the 'distance' $\delta_{i j}$ of the 'locations' (the alphabetic encodings) of component and system. We use the Lee (1958) measure $\mathcal{L}$, which is the minimum number of one-step manipulations required to change one loca-

\footnotetext{
8 This is in contrast to the arithmetic mean of the performances sometimes used [e.g. the $N K$ landscape model (Kauffman 1993)], in which a poorly performing performance of one can be compensated by a high performance of another, which is not realistic in non-modular products. Moreover, with an increase in the number of summands, there is a convergence in total performance [something akin to the complexity catastrophe in Kauffman (1993).].
} 
tion code into another. We assume that compatibility drops with distance and that the relative magnitude of the drop is a negative constant. As such, the compatibility is an exponential function:

$$
c_{i j}=e^{-x \delta_{i j}} \quad \text { with } \quad \delta_{i j}:=\frac{2 \mathcal{L}\left(s_{i}, s_{j}\right)}{N D} .
$$

The $s_{i}\left(s_{j}\right)$ is the (alphabetic) string for system $i$ (component $j$ ). The distance $\delta_{i j}$ is normalized by using that $N D / 2$ is the maximum Lee distance. Complexity $x$ determines the level of substitutability of components (and systems) for one another in a given product. If $x=0$, the components are perfectly interchangeable (as are the systems), as there is no effect on the overall product performance by doing so. The higher $x>0$ is, the more sensitive overall product performance becomes to the compatibility (distance) of component and system. We use this complexity $x$ as if the inverse of substitutability and treat it as one of our two independent variables.

\subsubsection{Effect of the governance form on search}

From the perspective of capability search, both governance forms (vertically integrated, specialized) have their advantages. A vertically specialized assembler has the advantage of being able to combine with all component capabilities offered bypotentially many - suppliers. As all of these suppliers are searching for and also finding component capabilities, the number of capabilities on offer also quickly grows. This is the combinatorial advantage as discussed in Sect. 2.3.

A vertically integrated firm has the advantage of having control over looking for component and system capabilities that are a proper fit. We model such a synergistic advantage by having an integrated firm look for components on the capability landscape tier in the alphabetic neighborhood of the system capability. The second advantage is that the integrated firm does not need to rely on suppliers that may go bankrupt after which the assembler has to switch to using possibly less compatible components. From the compatibility formula (2), it is apparent that the 'synergistic advantages' of integrated search are particularly great whenever substitutability is low (complexity $x$ is high).

\subsubsection{Radical search and multiple generations of product technology}

Given economic conditions specified later, firms engage in radical search to unlock a new landscape for the next generation of products. As consumers are willing to pay more for the new generation of products, there is a potential reward for firms to engage in radical search. The performance of a component and system of generation $g$ lies in the range $[0,1]$, and the performance of the whole product is in the range $[g, g+1]$.

\subsubsection{Imitation}

Imitation is operationally defined as manipulating the experimental combination of capability dimensions (abilities, skills, techniques, equipment) to decrease the distance 
from the experimental to the target capability. The probability of a successful step in the direction of the system/component capability is $i$, where $i$ is the imitability rate. The imitability $i$ is, just as complexity $x$, an independent variable in this paper. Consequently, given that the starting point on the landscape and the capability to be imitated are uncorrelated, the expected number of periods required to imitate the capability is $\frac{N}{4 i}\left(D-1_{D \text { odd }} \frac{1}{D}\right)$. The higher we set imitability $i$, the lower is the expected number of periods needed to imitate the target capability. This imitability $i$ is one of our two independent variables.

\subsection{Product launch, pricing, and withdrawal}

Each firm active on the consumer market has a portfolio of products that it actually produces and possibly sells on the market. If search yields a new product proposition, the firm evaluates whether it is eligible for production and, if so, adds it to the product portfolio. A product proposition is eligible for production if it outperforms one of the currently produced products or there is still room in the otherwise limited product portfolio. Moreover, the product must have a profit margin that is estimated to be positive. The flowchart for this procedure is found in Fig. 7.

If a firm has not yet produced and sold a particular product before, it has to start up production (for which a fixed cost is incurred) and launch it by giving promotional units to a number of consumers. These consumers will thus (possibly) drive further diffusion-substitution.

A selling firm (i.e. fully integrated or assembler) withdraws a product from the market and removes it from its portfolio if there has been no sales in the current period and there are no potential future sales. Note that also sales by any of the competitors of the same product or consumers currently still consuming the product forms potential future sales.

Firms set the price upon the product launch such that the value-for-money of the product (performance divided by price) is equal to the average value-for-money of products currently on the market. The rationale is that overpricing will stifle diffusion, while dramatic underpricing would hurt revenue too much. In case it is the first product on the market, the price is set to the maximum willingness-to-pay $p^{*}$.

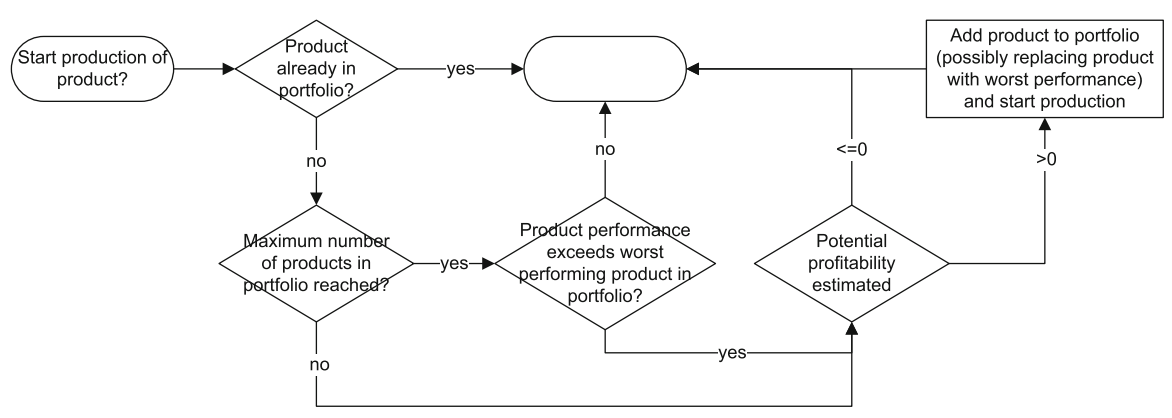

Fig. 7 The flowchart for deciding on whether or not to start producing a particular product 


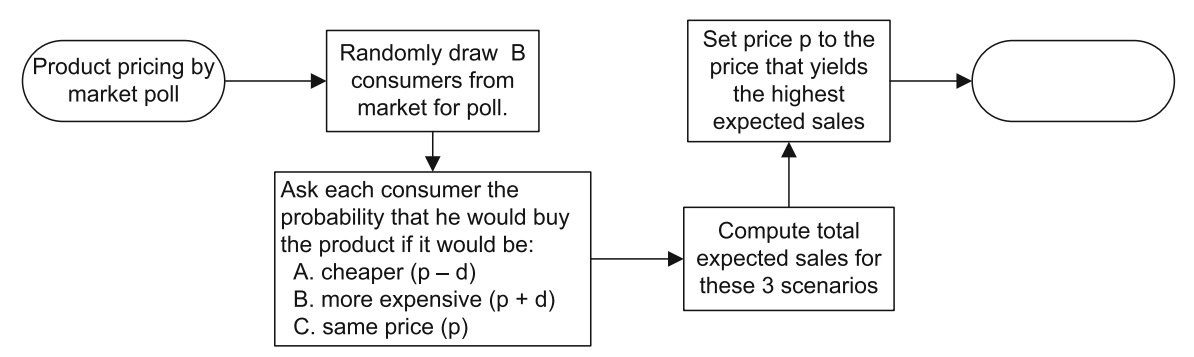

Fig. 8 The flowchart for product pricing process by polling consumers

Each period, each firm conducts a poll for each of its products to determine whether to change the price or not. In this poll, the firm randomly draws a fixed number $B$ of consumers from the population of consumers that currently consumes any product of the same product generation. The firm then asks each consumer the probability that it would buy the product in case of three scenarios: the price remains the same, is increased a little, and is decreased a little. These probabilities are in fact determined by the discrete choice model discussed later. The firm then maximizes expected sales (average probability times the (new) price) by increasing, decreasing or keeping the current price. Figure 8 contains the flowchart of this process.

With multiple firms and sufficiently discriminative consumers, there is profit erosion and eventually even a (marginal) loss to be expected. Firms will end up losing money, go bankrupt and exit. As demand is inelastic, a remaining monopolist can increase its price indefinitely. As such, we assume that a monopolist will not exit the industry. As we will see in Sect. 3.7, the monopolist will eventually have a high profit margin, which in turn attracts one or multiple entrants that will restore regular price competition.

\subsection{Consumer demand and substitution-diffusion}

The temporal pattern in consumer demand for new products is described by the classical Bass (1969) model. In this model, potential adopters of a new product are influenced by both mass media communications and interpersonal word-of-mouth. Mass media communications affect purchase decisions mostly in the early stage of the product lifecycle, while interpersonal communications dominate after this (see Rogers 1995, pp. 79-82). In the model in this paper, consumers that have consumed their unit of product have to buy a new one. In general, consumers have numerous products to choose from, often even products of different generations. Macro-level substitution-diffusion models extending Bass (1969) describe how products of newer generations gradually diffuse in the consumer population and how these products thus substitute the products of old generations (Norton and Bass 1987; Fisher and Pry 1971; Marchetti and Nakicenovic 1979). In these macro-level models consumers ultimately do not differ in their propensities to adopt particular products (or even newer generations of products). In reality, consumers differ in their purchasing power, the willingness-to-pay, exposure to mass media, connections to consumers that may already have purchased a product, etc. Rogers (1995) takes a micro-level perspective on adoption decisions and argues 


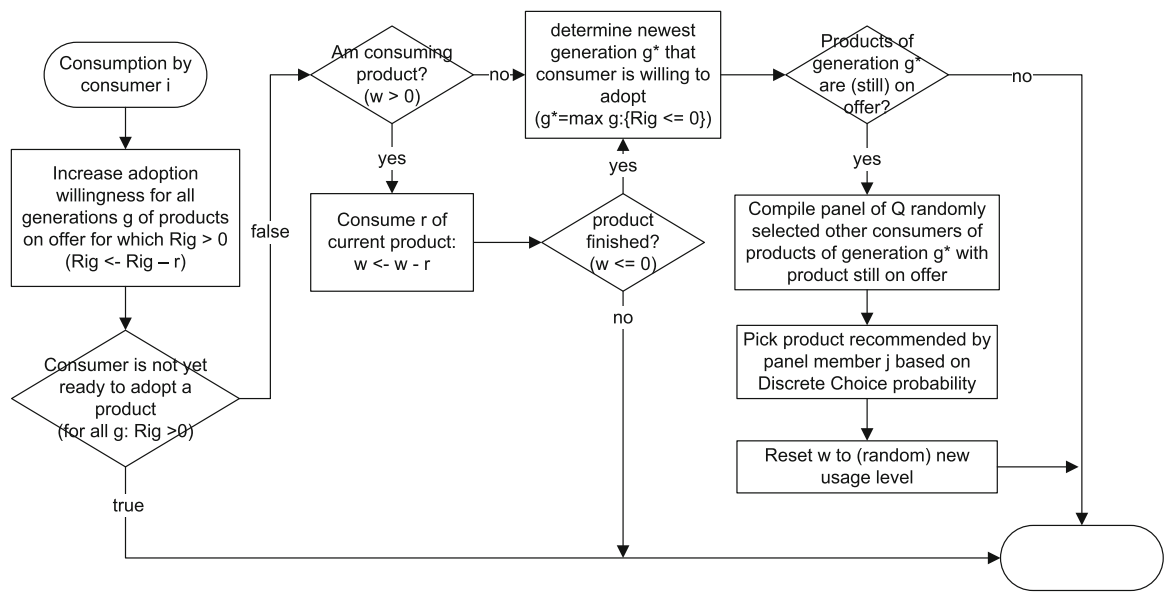

Fig. 9 The flowchart for the procedure how a focal consumer decides when to purchase what product of which generation

that individual characteristics of consumers in combination with exposure through mass media and word-of-mouth determines the actual adoption propensity. In Rogers' perspective consumers range from being 'innovators' with a high propensity to adopt new products to 'laggards' that are reluctant to adopt. Rogers' perspective also allows modeling of micro-level phenomena such as Veblen's conspicuous consumption and bandwagon dynamics (cf. Leibenstein 1950).

To reproduce the demand dynamics in the product life-cycle, the demand model in our neo-Schumpeterian model features an initial 'mass launch' for each product followed by a relatively autonomous substitution-diffusion due to 'word-of-mouth' of heterogeneous consumers. Figure 9 contains the flowchart of how a focal consumer decides when to purchase what product of which generation. The mechanisms and variables in this flowchart are explained in the following subsections.

\subsubsection{Product choice and word-of-mouth}

Through word-of-mouth, a consumer learns about the existence and performance of products. We assume that, upon having to buy a new unit of generation $g$, a consumer has talked to $Q$ other consumers, each currently consuming a product that is still produced. Of the products of each of these $Q$ consumers, the focal consumer knows the performance (see Eq. 1) and the current price. We follow consumer choice literature in which consumers care for the value-for-money. The value-for-money is operationally defined most commonly as the ratio of quality and price (Sweeney and Soutar 2001). Here, we define the value-for-money of a product as:

$$
v=\frac{q}{q^{*} p}
$$


The value-for-money is in essence how much value (performance $q$ ) the consumer gets per dollar (price $p$ ). We normalize $q \in(0,1]$ by dividing by $q^{*}$, the highest performance yet found, to make the payoff independent of the absolute performances. Given that $q / q^{*}$ reflects the value of the product to consumers, we operationally refer to this ratio (after multiplying with a scalar $W=150$ ) as the willingness-to-pay.

Given that the focal consumer is not perfectly rational, nor perfectly informed, and makes errors in assessing the performance of products, we assume that the focal consumer does not pick the product that maximizes the value-for-money, but picks a product according to the discrete choice model. The discrete choice model is ubiquitous in economics, psychology, marketing, etc. and specifies how a consumer picks a particular product probabilistically from a set of products based on the utilities of these products (McFadden 1974; Train 2002; Anderson et al. 1992). In line with our case, we have the focal consumer favor the product recommended by consumer $i \in\{1, \ldots, Q\}$ according to the following multinomial logit formula:

$$
p_{i}:=\frac{e^{\gamma v_{i}}}{\sum_{j=1}^{Q} e^{\gamma v_{j}}}
$$

The scaling parameter $\gamma \geq 0$ in this discrete choice probability specifies the preference of consumers for products with high value-for-money. If $\gamma \rightarrow \infty$, consumers pick the product with the highest value-for-money and are pure maximizers, while, if $\gamma \downarrow 0$, consumers pick a product uniform randomly and do not care about value-for-money.

\subsubsection{Consumption rate}

In many neo-Schumpeterian models, consumers buy a unit of product every period. However, in that case, diffusion-substitution is rapid and the market shares of products (and firms) evolves highly disruptive. However, we seek to reproduce the product lifecycle dynamics including the gradual emergence of a dominant design and profit erosion. As such, we assume that consumers differ in how quickly they consume a unit of product and, hence, how often they need to buy a new unit of product. We implement this by having each consumer $j$ consume a product at a rate $r_{j}$ uniform randomly drawn from $\{r /(1+r \rho), \ldots, r, \ldots, r /(1-r \rho)\}$ (or, alternatively, having each consumer $j$ purchase a unit after a number of periods uniform randomly drawn from $\{1 / r-\rho, \ldots, 1 / r, \ldots, 1 / r+\rho\})$. Hereby $\rho \in \mathbb{N}^{+}$smaller than $1 / r$ and $r>0$ the average consumption rate.

\subsubsection{Product launch and willingness-to-adopt}

A firm launches a product by starting a mass media campaign persuading a fixed number of random consumers to purchase its product. These consumers will start to inform other consumers, thus potentially generate new demand for the product. However, apart from having different rates of consumption, consumers also have a different willingness to adopt a newly launched generation of products. Rogers (1995) classifies consumers as innovators, early adopters, early majority, late majority, and laggards, 
whereby innovators buy products of a new generation right after the launch (e.g. bought a smartphone in 2007), while laggards are the last consumers in a population to buy a new product (e.g. have not yet bought a smartphone in 2015). The differences in Rogerian adoption willingness is the primary cause of the gradual substitution.

We implement this by drawing the willingness $R_{j}$ of a consumer $j$ from $\mathcal{N}(\mu, \sigma)$ with $\mu=3 \sigma$. For $R_{j}$ close to zero, consumer $j$ is an innovator, for $R_{j}$ close to $\mu+3 \sigma$, the consumer is a laggard. With $T_{j g}$ the point in time when consumer $j$ is informed of a product of generation $g$, consumer $j$ is willing to buy a product of generation $g$ as of time $t=T_{g j}+R_{j}$. Once a consumer has finished its current unit of product (possibly of an old generation $g^{\prime}$ ), and the consumer has to buy a new unit of product, the consumer purchases a product of the newest generation he is willing to buy. Under the assumption of availability of products of yet discovered generations (which is ensured due to our entry criteria), all first-buyers have purchased their first unit of product of generation $g$ in approximately $6 \sigma / r$ periods after the launch.

\subsection{Entry and exit}

A particularly distinct element of neo-Schumpeterian models is population-level learning by (i) deselection of evolutionary unfavorable strategies due to exit of firms and (ii) active propagation of apparently favorable strategies due to entry of firms imitating strategies of existing firms.

Upon the initialization of the first run of an industry, there is a fixed number of firms that immediately enters. To prevent favoring a particular strategy, we initialize $A$ firms with all $A$ combinations of integration and outsourcing before and after the emergence of the dominant design. From that moment onward, firms enter and exit the industry fully endogenously. A firm exits the industry if its capital drops below the bankruptcy level (zero). However, we assume that a monopolist succeeds in persuading creditors not to file for bankruptcy. Given the inelasticity of demand, the monopolist can raise its prices (and the pricing heuristic depicted in Fig. 8 in Sect. 3.5 ensures it does), and with the increase in profit margin, entry becomes attractive for potential entrants again. Once a new firm enters the industry, the industry no longer is a monopoly, and the old exit conditions are restored.

Following Nelson and Winter (1982), we assume that there is always a firm waiting outside the industry for the industry conditions to meet its entry criteria to then enter. Each period, the potential entrant (imperfectly) imitates the strategy of the firm with the highest discounted cumulative capital. Upon imitation, the potential entrant changes the governance strategy in 5\% of the cases. This constitutes local search in the governance strategy. Following this strategy, the potential entrant determines whether it becomes entrepreneur or manufacturer and whether it would then enter or not according to the criteria on profit margin and design dominance given below.

We follow the characterizations of manufacturing firms over the product life-cycle of Utterback and Abernathy (1975) and Klepper (1996). In the early phase of the PLC, the entrants are small, flexible, and innovative firms ('entrepreneurs') that tolerate high uncertainty to reap high profit margins. In the growth and mature phases of the PLC, the entrants are big, capital intensive production houses ('manufacturers') that 
reap low profit margin with dedicated production equipment under low uncertainty. Operationally, we assume that entrepreneurs are willing to enter when (i) the profit margin for the newest generation of products is high, (ii) the design dominance in that generation is low, and (iii) there are not too many competitors. In this case, there are considerable market and technological opportunities. We assume that a manufacturer enters when (i) the profit margin (for the latest generation of products) is not too low, (ii) the design dominance in that generation is already relatively high ('limited technological uncertainty'), and (iii) there are only a few competitors. In this case, the manufacturer can recover investments while it is unlikely that a switch in production is required. The entry criteria revolve around the profit margin and design dominance. For the design dominance statistic, we follow many neo-Schumpeterian models with entry and use a concentration index for generation $g$ :

$$
H_{g}^{2}=\frac{\sum_{i \in M_{g}} s_{i}^{2}}{S^{2}},
$$

where $s_{i}$ with $i \in M_{g}$ is the market share of the $i$ th product of generation $g$ on the market (possibly offered by more than one firm), $M_{g}$ is the index set of products of generation $g$ currently on the market, and $S$ is a normalization constant ${ }^{9}$ (over all generations). We compute this $H$ for each generation $g$ of products on the market. Given the volatility of $s_{i}$, particularly in the onset phase, we have firms use an exponentially smoothened $\hat{H} \leftarrow h H+(1-h) \hat{H}$ with smoothing rate $h=1 \%$. For the profit margin per generation, we use the weighted average of the profit margins of all products of that generation. We again have firms use an exponentially smoothened average profit margin $\hat{P}$ as there is volatility due to introduction and withdrawal of products. Given the different tolerances for number of competitors, the entry rates for entrepreneurs and mass-manufacturers differ. Entrepreneurs enter with probability $e(x)=1 / x$ (with $x$ the number of firms) if $\hat{P}>P^{e}$ and $\hat{H}<H^{e}$. Manufacturers enter with probability $e(x)=a /(1+x)$ with $0<a<1$ if $\hat{P}>P^{m}$ and $\hat{H}>H^{m}$.

\subsection{Cost structure}

We treat the cost structure as a mediating variable. We pick a cost structure that closely meets the classical product life-cycle notions of entrepreneurial activities before and mass-manufacturing activities after the emergence of the dominant design, see Utterback and Abernathy (1975). We assume that an entrepreneur runs a job shop, which is a flexible production facility that facilitates switching to making another product at relatively low costs. However, production in a job shop relies on generic tools rather then specialized equipment, is labor intensive, and requires relatively skilled and thus expensive employees. Moreover, the batch size is relatively small such that there are limited positive scale economies. All in all, job shops have high unit production costs.

\footnotetext{
${ }^{9}$ We do not pick $S^{2}=\left(\sum_{i} s_{i}\right)^{2}$. In our case, $s_{i}$ need not sum up to 1 as there may be potential adopters that still need to do their first purchase. As we use $H$ to reflect market opportunities, we rather take $S=r N$, where $r N$ is the average demand per period (in number of consumers) with all repeat-buyers. Due to first-buys and future peaks in sales due to launches, the $H$ may be temporarily higher than 1 .
} 
In contrast, a mass-manufacturer has dedicated production equipment, a relatively low number of employees to run the plant, and thus comparatively low labor costs. A mass-manufacturer produces big batches to reap positive scale economies and thus has low unit production costs. However, given the dedicated production equipment, there are high production switching costs.

Moreover, the vertical governance form affects the immediate production costs. Vertically specialized system producers incur transaction costs to contact, contract, and control suppliers as opposed to in-house production. Firms also incur costs when changing the governance form. Integration requires investments in production facilities, while these facilities are scrapped or divested upon outsourcing. In order to ensure that firms are quickly acquiring an evolutionary beneficial governance strategy during simulation runs, we reduce noise in firms' financial performance caused by cost particularities by assuming that firms in each of the tiers face the same cost structure. To prevent further escalation in the number of parameters, we assume that the manufacturing costs in the up- and downstream tiers are equal and only depend on whether the firm runs a job shop or dedicated mass-manufacturing equipment. However, we do assume that the system producers in the downstream tier incur the transaction costs for purchasing components from the vertically specialized component producers in the upstream tier.

Apart from these periodic manufacturing costs, there are costs of incremental research, imitation, and radical research. We assume that costs for incremental research and imitation are negligible relative to costs of radical research. The costs for radical research are set so high that any firm can only produce a few commercially unsuccessful radical products before going bankrupt.

The parameter values used in the standard simulation runs are provided in "Appendix 1". In simulation experiments, we have validated mediating effects of these costs on the governance forms emerging, e.g. if governance change becomes extremely expensive, the emerging strategy is to stick with the current governance form. For an elaborate discussion on the parameter choices, see Sect. 4.1.

\section{Results}

In this section, we present, analyze, and interpret the simulation results. In Sect.4.1, we discuss our parameter choices and how our model reproduces the stylized facts of a product life-cycle. In Sect.4.2, we present experimental results on how imitability and complexity (as inverse of substitutability) affect the emerging governance forms in the era of ferment and the era of incremental change. We statistically analyze and conceptually interpret the simulation results, and compare them with our theoretical predictions.

\subsection{Analysis of the simulated industry evolution}

In this subsection, we cross-validate the simulation results with common stylized facts in evolutionary economics for industry evolution under homogeneous demand. We start off with a discussion of the parameter values chosen. We then establish that 
our simulation model of the product life-cycle indeed produces results that feature consecutive product life-cycles with eras of ferment and incremental change with the common stylized facts. We then discuss the effects of our parameter choices on the stylized life-cycles.

\subsubsection{Parameter settings}

The parameter values for the cost structure, capability landscape, demand and pricing modules, and strategy parameters have been attuned to one another to ensure that the simulation results feature common stylized facts. In this parameter attuning, we balanced the ratio of feasible capabilities (tuned by the landscape parameters), the periodic manufacturing costs, and possible revenue (as tuned by number of customers, maximum willingness-to-pay, diffusion-substitution rate, and price adjustment rate). The conceptual explanation is that if there are fewer feasible capabilities, firms have to search longer, the average search costs per discovery are higher, such that the total revenue must be higher to ensure that at least some firms succeed in recovering the search costs. In fact, during experimentation with the market and pricing modules determining the revenue and the technology landscape module determining the average search trajectory length, we noticed that the parameter settings are relative rather than requiring a particular absolute setting. Ultimately, we picked parameter values that have an 'economically sensible interpretation' yet maintain an acceptable computation time. To this end, we limited the market size to 4000 consumer agents. More consumers slows down simulation runs substantially. Using this market size, we then picked the willingness-to-pay, search costs, and initial capital endowments. Given the development of capital, we tuned the fraction of feasible capabilities in the landscape search module and the scale and tail of the performance levels. After selecting the value for these parameters, there are only a few parameters left to specify.

We pick values for the parameters for the search strategy (imitation, exploration, radical search), adoption of newly found products, and entry, to have an 'economically sensible' interpretation. With regard to imitation, our idea is that firms will only engage in the-possibly lengthy-imitation process if the performance is more than $y \%$ better than the firms currently own top products. As imitation will inevitably mean that this product is also taken into production, and production switching is argued to be more costly for manufacturers, the improvement for manufactures must be even greater than for entrepreneurs. Something similar holds for discovered products in recombination of capabilities: if a product is not more than $z \%$ better than a firm's top product, the firm will not take it into production because consumers have only a small probability of buying it.

In our operational definition of entry and parameter choices, we have ensured that firms will not enter if the profit margin is too low or if the design dominance is too high. Even if a firm succeeds in finding a top product that consumers switch to, the expenses may not be recovered before other firms find a radical breakthrough. In our operational definition of radical search and parameter choices, we have ensured that firms will start radical search if the profit margin is very low and the design dominance is very high. After all, there are then only limited opportunities to make a profit in this generation of product technology. In our operational definition of the business 
strategy and parameter choices, we have ensured that firms will not switch to massmanufacturing facilities whenever they are expected to have to switch production due to technological turmoil. After extensive experimentation, we picked the decision thresholds as specified in "Appendix 1".

\subsubsection{Stylized facts reproduced}

The simulation results are externally valid in that - for our choice of parameters-our model robustly produces the stylized facts of the product life-cycle for homogeneous demand: swarm-in/shake-out of firms, product turmoil followed by emergence of a dominant design, profit erosion, and triggering of radical research.

For the illustration, we initialize our application to simulate an industry evolution for $X=10,000$ periods. We set the independent variables imitability $i=0.025$ and complexity $x=4.0$, and - anticipating results discussed later-preset the governance strategy to integration in the era of ferment and vertical specialization in the era of incremental change. The simulation results are plotted in Fig. 10. The vertical bars (here at about periods 3750 and 7250) in all subfigures signify radical innovation punctuations at which an era of ferment starts. The era of incremental change is associated with a high level of concentration of particular products. Figure 10c contains square curves (different colors only for clarity) for the life-spans and performances of the various products on the market. During the intervals of roughly [0, 2000] and [3750, 5000] there are many product introductions and removals, and the performance levels of these products varies much but tends to increase. During the intervals [2000, 3750] and $[5000,7250]$, there are only very few product introductions and there is one 'top product' that persistently dominates. Figure 10e contains the curves of the smoothened design dominance (see Eq. 4 in Sect. 3.7). We have three curves (with different colors for clarity) starting at the radical innovation punctuations, each indicating the dominance of one generation of product technology. We see that the curves start low, rise steeply, and then level off when the top product technology starts to dominate. On the basis of these simulation results, we argue that our simulation model reproduces the stylized fact that there is technological turmoil in the era of ferment followed by design dominance followed by the era of incremental change.

Figure 10a contains the curves of the number of firms. The blue dotted curve is the total number of firms. The purple dashed curve is the number of integrated firms. The khaki continuous line is the number of system assemblers, while the green dotdashed line is the number of component suppliers. Right after the radical innovation punctuations at period 0, 3750 and 7250, there is a steep increase of the total number of agents. With the design dominance-plotted in Fig. 10e-approaching 1, and the technological turmoil almost over (see the intervals mentioned above), the (total) number of firms steeply drops. We also see that the firms switch their governance form from vertical integration to vertical specialization. On the basis of these simulation results, we argue that our simulation model reproduces the stylized fact that there is a swarm-in of firms after a radical breakthrough and a shake-out around the moment that one or a few particular product technologies start(s) to dominate.

Figure 10f contains plots of the smoothened average profit margin of products on the market, per generation. We see that there is a very steep rise just after the radical 


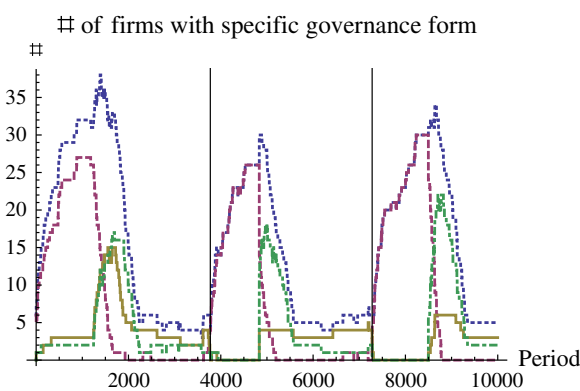

(a)

Product proposition performance Performance

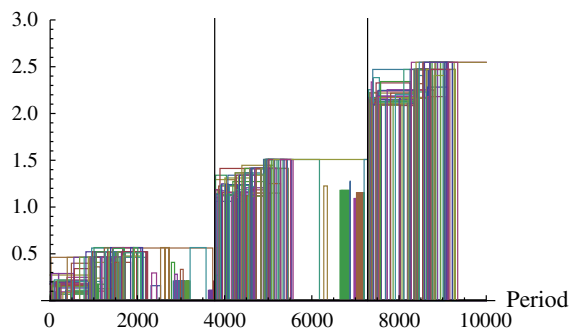

(c)

Design dominance

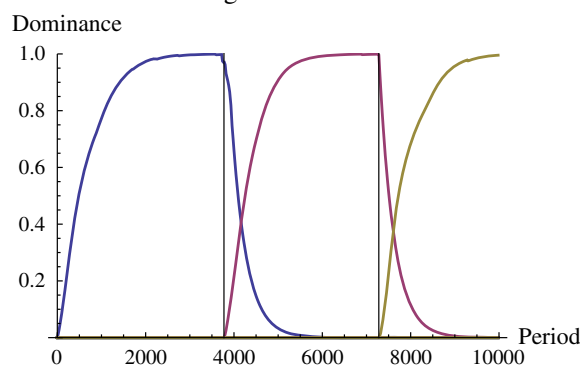

(e)

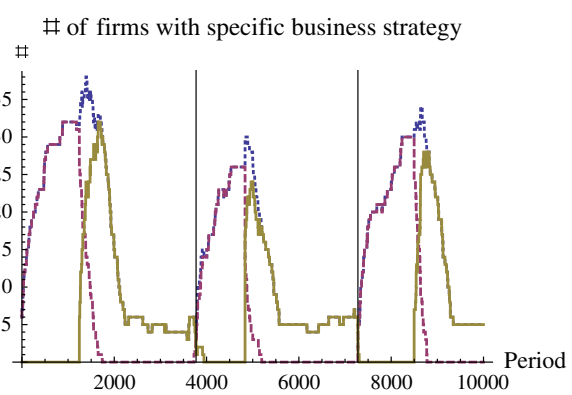

(b)

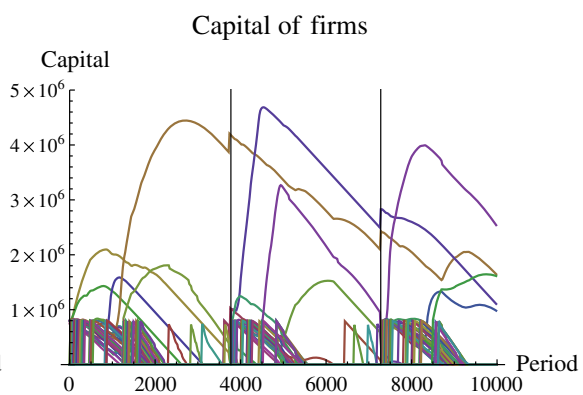

(d)

Avg profit margin per generation

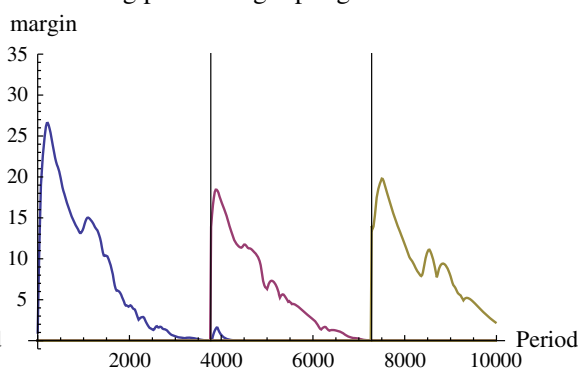

(f)

Fig. 10 Plots of various statistics of an industry evolution with three life-cycles. A detailed description of the figures and the curves is found in Sect.4.1.2. a Number of firms of each type. b Number of firms per business strategy. c Performance. d Capital of the firms. e Design dominance $\hat{H}$. f Average (smoothened) profit margin

breakthrough, to then decrease and approach zero. We see three consecutive curves (with different colors for clarity), one for every generation of product technology. The steep increase is caused by the fact that we use the smoothened average profit that starts at 0. As explained in Sect. 3.5, the price of the first product of a particular generation is equal to the maximum willingness-to-pay $p^{*}$. Note that the average price for products of a certain generation is decreasing, while Fig. 10c indicates the product performance is increasing. The temporary increase in profit margin around 4000 is due to a monopolist raising its price for (inelastic) demand from consumers that are still 
consuming an old generation product (see Sect. 3.5). On the basis of these simulation results, we argue that our simulation model reproduces the stylized fact that there is profit erosion due to price competition.

There are two figures that are not immediately related to the stylized facts. Figure $10 \mathrm{~b}$ contains the curves of the number of firms per business strategy (entrepreneur, manufacturer). The blue dotted curve is the total number of firms, the purple dashed curve the number of entrepreneurs, and the khaki continuous curve the number of manufacturers. We see that endings of the eras of ferment (around periods 2000 and 5000) coincide with the switching of firms from the entrepreneurial to the massmanufacturing business strategy.

Figure 10d contains curves of the capital for each firm. The colors of the curves differ to be able to distinguish one from the other. For some firms, the capital increases first and only after some time starts to decrease. Some firms exist over multiple product life-cycles. Other firms fail to realize a (substantial) market share and exit shortly after entry.

\subsubsection{Effects of parameter changes on the stylized product life-cycle}

At present, we have tuned the parameters for the cost structure, technology landscape, demand and pricing modules, and strategy parameters to ensure that the simulation results feature the stylized facts as described above. Neo-Schumpeterian models lend themselves for treating these parameters as mediating variables and to study the effect of these parameters on the industry evolution. Given the number of parameters in our model, we cannot discuss all possible variations.

As discussed in detail in Sect.4.1.1, there is a relative balance between the ratio of feasible capabilities (tuned by the landscape parameters), the periodic manufacturing costs, and possible revenue (as tuned by number of customers, maximum willingnessto-pay, diffusion-substitution rate, and price adjustment rate). If we alter the relative number of peaks in the technology landscape by changing $N, D$, this has obvious implications. For instance, increasing $N$ or $D$ requires longer search, and firms thus incur higher search costs before finding feasible capabilities, and thereby more bankruptcies (and more entries, see Sect.3.7). Simulation studies revealed that the number of consumers and maximum willingness-to-pay $p^{*}$ lengthen the product life-cycle. The underlying cause arguably is that the total market revenue increases. Decreasing the number of consumers in the price poll increases the volatility in pricing. Lowering the profit margin at which firms start doing radical research will extend the era of incremental change of the product life-cycle. Other parameters, like the transaction and periodic operating costs, merely change the slope of the capital curves.

The simulation outcomes consistently feature the stylized facts of the product lifecycle for different, non-extreme values of imitability and complexity (substitutability). However, the higher the complexity, the more detrimental technological distance between component and system is, and the lower the average product performance becomes. As the probability of bankruptcy relates to the relative product performances, the market concentration is lower in case of high than is in case of low complexity. The differences in revenue between firms drop with complexity and there are fewer big players. Furthermore, the lower imitability, the longer imitation takes, the more 
substitutable/modular $\mathrm{x}=0.0$

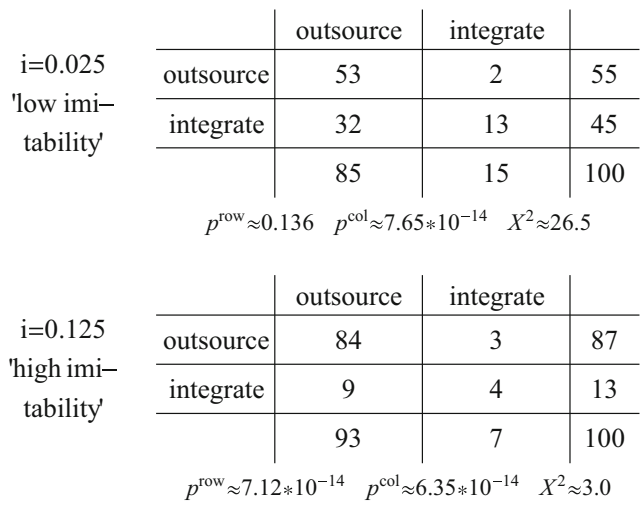

complex $\mathrm{x}=8.0$

\begin{tabular}{c|c|c|c} 
& outsource & integrate & \\
\hline outsource & 16 & 0 & 16 \\
\hline integrate & 58 & 26 & 84 \\
\hline & 74 & 26 & 100 \\
$p^{\text {row }} \approx 3.42 * 10^{-13} \quad p^{\text {col }} \approx 2.82 * 10^{-7} \quad X^{2} \approx 58.0$
\end{tabular}

\begin{tabular}{|c|c|c|c|}
\hline & outsource & integrate & \\
\hline outsource & 23 & 2 & 25 \\
\hline \multirow[t]{2}{*}{ integrate } & 68 & 7 & 75 \\
\hline & 91 & 9 & 100 \\
\hline
\end{tabular}

Fig. 11 Governance patterns emerging in our simulation for low and high imitability and low and high complexity (high and low substitutability). Row (column): type of governance form picked in the era of ferment (incremental change)

firms with top products appropriate the value of their products. These firms with top products will thus grow a bigger market share and gain more capital, which culminates in a more concentrated industry.

\subsection{Governance patterns}

We report the findings of extensive simulation runs for four combinations of imitability (low $i=0.025 /$ high $i=0.125$ ) and complexity (low $x=0 /$ high $x=8$ ) and provide statistical analysis of the governance patterns emerging. For each of these four combinations, we simulate the industry evolution for 50,000 periods, and for 100 different seed values. For each seed value, we take the governance strategy with the highest (discounted) capital stock at the end of these 50,000 periods and register the governance form in both the eras of ferment and incremental change. We thus construct a $2 \times 2$ contingency table with the governance form in the era of incremental change on the $X$-axis and the governance form in the era of ferment on the $Y$-axis. Figure 11 contains a $2 \times 2$ table with the four scenarios for the particular settings for imitability and complexity, with the contingency table of the simulation results in each cell of this table. We first discuss the statistics used and then the simulation outcomes, their statistical analysis, and the interpretation thereof.

\subsubsection{Statistics used}

To test whether firms prefer one or the other governance form in either one of the eras (ferment and incremental change), we point out that under the null hypothesis of no preference, the count data follows a Binomial distribution with $p=\frac{1}{2}$. Suppose that we run the simulation $n$ times and find that the superior governance strategy is $n_{o}$ times to outsource and $n_{i}$ times to integrate (with $n=n_{o}+n_{i}$ ). The probability of this observation $\left(n_{o}, n_{i}\right)$ under $H_{0}$ is equal to $\left(\begin{array}{c}n \\ n_{o}\end{array}\right) p^{n}$. 
The $P$-value of observing $\left(n_{o}, n_{i}\right)$ or a more extreme outcome under the nullhypothesis is defined as $\mathbb{P}\left(B<\min \left\{n_{o}, n_{i}\right\} \mid H_{0}\right)$ with $B \sim \operatorname{Bin}\left(n, \frac{1}{2}\right)$. The $P$-values are reported in Fig. 11, where $p^{\text {row }}\left(p^{\mathrm{col}}\right)$ is the $P$-value for a preference for one or the other governance form in the era of ferment (era of incremental change).

To test whether the emergence of the dominant design changes the choice of firms to outsource or integrate, we use McNemar's Chi square statistic $\chi^{2}=\frac{\left(n_{12}-n_{21}\right)^{2}}{n_{12}+n_{21}}$ for matched-pair homogeneity. McNemar's non-parametric test based on this statistic signals whether or not there are significantly many counts in the off-diagonal cells. The $\chi^{2}$ values in Fig. 11 indicate whether or not there is a significant change in preference from outsourcing to integration or vice versa. With one degree of freedom, the McNemar Chi square statistic $\chi^{2}$ for matched-pair homogeneity leads to rejection of $H_{0}$ of equality if $\chi^{2}>3.84$ (5\% significance level).

In addition, we use McNemar's statistic to test whether-within the same era-a certain change in parameter value also changes the preference for a certain governance form. We do so by running the simulation with exactly the same parameter settings and seed value, changing only this one parameter (here, complexity $x$ or imitability $i$ ). Table 3 presents the results.

\subsubsection{Statistical findings and interpretation}

In Table 2, we see that the dominant pattern is to (i) outsource in the era of incremental change (for occasional recombination and upstream scale economics) and (ii) to integrate under low substitutability and to outsource under high imitability in the era of ferment.

In the era of incremental change, firms are significantly often vertically specialized (low $p^{\text {col }}$ values) regardless of imitability or complexity/substitutability. In Table 3 , we see that complexity decreases the propensity to outsource: if complexity is higher, incompatibilities with a newly discovered complement are more likely, so the benefit of being able to substitute is lower. Interestingly, imitability mediates the effect of increasing complexity. If imitability is low, there is significantly less outsourcing (more integration) when complexity increases. The conceptual interpretation is that, given that it takes - in expectation-many periods to imitate a competing product,

Table 2 McNemar statistics on change in vertical governance strategy from the era of ferment to the era of incremental change for different levels of complexity and imitability

\begin{tabular}{lllll}
\hline \multirow{2}{*}{ Complexity } & Imitability & Era & McNemar $\chi^{2}$ \\
\cline { 3 - 4 } & & Ferment & Incremental change & \\
\hline$x=0$ & $i=0.025$ & $55 \%$ outsources & $85 \%$ outsources & $\chi^{2}=26.5$ \\
\multirow{2}{*}{$x=8$} & $i=0.125$ & $87 \%$ outsources & $93 \%$ outsources & $\chi^{2}=3.0$ \\
& $i=0.025$ & $84 \%$ integrates & $74 \%$ outsources & $\chi^{2}=58.0$ \\
& $i=0.125$ & $75 \%$ integrates & $91 \%$ outsources & $\chi^{2}=62.2$ \\
\hline
\end{tabular}

With one df, the McNemar test rejects $H_{0}$ (no change) if $\chi^{2}>3.84$ (5\% significance level) 
Table 3 McNemar statistics on change in vertical governance strategy upon a change in capability regime parameter value

\begin{tabular}{llll}
\hline $\begin{array}{l}\text { Value fixed } \\
\text { parameter }\end{array}$ & $\begin{array}{l}\text { Change in value } \\
\text { controlled parameter }\end{array}$ & Era for which test is conducted & \\
\cline { 2 - 4 } & & Ferment & Incremental change \\
\hline$x=0$ & $i=0.025 \rightarrow 0.125$ & More outsourcing $\chi^{2} \approx 17.0$ & No sign. diff. $\chi^{2} \approx 0.529$ \\
$x=8$ & $i=0.025 \rightarrow 0.125$ & No sign. diff. $\chi^{2} \approx 3.60$ & More outsourcing $\chi^{2} \approx 7.26$ \\
$i=0.025$ & $x=0 \rightarrow 8$ & More integration $\chi^{2} \approx 4.57$ & More integration $\chi^{2} \approx 11.1$ \\
$i=0.125$ & $x=0 \rightarrow 8$ & More integration $\chi^{2} \approx 46.0$ & No sign. diff. $\chi^{2} \approx 2.91$ \\
\hline
\end{tabular}

With one $\mathrm{df}$, the McNemar test rejects $H_{0}$ (governance forms are not affected by the change in regime property) if $\chi^{2}>3.84$ (5\% significance level)

the value of an integrated product can be appropriated. For high imitability, $i=$ 0.125 , the integrated product is imitated near instantly, the value is not appropriated by the inventor, so developing an integrated solution is less attractive, which further discourages integration (although not significantly). Moreover, the integrated firm does not enjoy the benefits of being able to switch to a newly discovered complement (or being switched to in case of a component supplier). Particularly under low complexity, a specialized supplier with a top component enjoys scale economies and so do his customers. Conclusively, firms prefer outsourcing in the era of incremental change. However, there is less outsourcing whenever complexity increases, particularly when the value of synergistically attuned products can be appropriated more (i.e. under low imitability).

In the era of ferment, there is no clear preference for either outsourcing or vertical specialization. However, we see that firms vertically integrate more often with an increase in complexity (also see Table 3 ). The propensity to outsource more under low complexity and integrate more under high complexity further polarizes with imitability. The conceptual explanation is that with an increase in imitability, appropriability and hence the value of integration decreases. Whenever complexity is higher, there is more integration to overcome compatibility issues. So, the trade-off of high performance plus exclusion/appropriation through integration and easy recombination and decentralized search through specialization tilts in favor of vertical integration with an increase in complexity. However, this is countered by an increase in imitability as this lowers appropriability.

We find that costs mediate in the obvious direction. If transaction costs drop, there is more outsourcing, especially in the era of incremental change. Furthermore, the higher the costs of changing the governance form, the more firms stick to a single governance form over both eras.

\subsubsection{Comparing theoretical predictions with statistical results}

Next, we compare our simulation results contained in Table 4 with our hypotheses contained in Table 1. 
Table 4 Emerging governance forms in both eras subject to imitability and substitutability

\begin{tabular}{lll}
\hline & Substitutability & \\
\cline { 2 - 3 } & Low $(x=8)$ & High $(x=0)$ \\
\hline Imitability & & \\
Low $(i=0.025)$ & $\begin{array}{l}\text { Integration for attuning and } \\
\text { exclusion followed by outsourcing }\end{array}$ & $\begin{array}{c}\text { Indifference in era of ferment } \\
\text { followed by outsourcing }\end{array}$ \\
High $(i=0.125)$ & $\begin{array}{c}\text { Integration for attuning, followed by } \\
\text { outsourcing }\end{array}$ & Outsourcing in both eras \\
\hline
\end{tabular}

We see that whenever the effects of imitability and substitutability both indicate to outsource or both indicate to integrate (i.e. the two on-diagonal cases), our simulation results confirm that this effect occurs during the era of ferment. However, whenever integration is predicted (the case with low substitutability and low imitability), that the tendency to integrate is dominated by outsourcing during the era of incremental change. Favorable cost differentials of outsourcing to a supplier with a top component dominate the - as we already argued in Sect.2.3-relatively weak factors in favor of integration. Whenever the effects of imitability and substitutability are conflicting (i.e. the two off-diagonal cases), there is theoretical ambiguity on the governance form. We see that, in the era of incremental change, decentralized search and favorable cost differentials dominate benefits of integration. Under high imitability and low substitutability, we see that in the era of ferment, under technological turmoil, there is no significant preference for either integration or specialization. Under our parameter choices, decentralized search by specialization gives about as much competitive advantages as does appropriation through integration. As firms are entrepreneurs with flexible job shops, there is no cost advantage of outsourcing.

\subsubsection{Reproducibility and robustness checks}

An extensive number of runs for different seed values revealed that the results are reproduced for the parameter settings given in "Appendix 1". In Sect.4.1.1, we explained that the number of feasible capabilities on the landscape, the periodic manufacturing costs, and possible revenue are attuned to one another. Big changes to parameters in either one of these modules will generally cause more variance in the simulation outcomes and less significant results. The explanation of this increase in variance is sought in the fact that disruptive change in parameters weakens the discriminative power of the selection in the model. If costs increase or payoff decreases disruptively, firms generally live shorter and have relatively few search steps, such that their survival highly depends on 'serendipitous' discovery of capabilities. If costs decrease or payoff increases significantly, there are relatively few firms that go bankrupt, industries get a low clockspeed, and there are only few 'selective' technology punctuations. In both cases, there is considerable uncertainty in which strategy survives, and thereby considerable variation in the emerging governance strategy. 
The values for the parameters of these modules are chosen such that the simulated economy does not suffer weak selective power due to the longevity of the industry, nor suffers weak discriminative power due to mostly accidental survival. Experimentation runs have revealed that incremental change to parameters has only moderate effects on the simulation outcomes. That said, given the parameter values for these modules, there still are parameters that mostly affect the costs and chances of finding top capabilities depending on the governance strategy. The most obvious parameter is the transaction cost when buying components upstream. Simulation studies revealed a dominant effect of transaction costs: if transaction costs drop, there is more outsourcing, especially in the era of incremental change. Other obvious parameters are the costs of vertical integration and outsourcing. The higher these costs, the more firms stick to a single governance form over both eras.

\section{Discussion and conclusions}

Following recent endeavors in economic and organizational literature, we studied the governance forms in the different stages of the homogeneous product life-cycle. In this literature, there is, particularly, disagreement over the governance form to be preferred in the early stage after a technological breakthrough and before the emergence of a dominant design. We postulated that differences in the governance strategies are due to differences in the capability regime. We presented an advanced neo-Schumpeterian agent-based simulation model of a two-tier industry that robustly reproduces the stylized facts of industry evolution with consecutive product life-cycles. We subsequently used this model to study emerging governance patterns by firms evolutionary learning the governance strategy for different levels of imitability and substitutability of the capabilities. The simulation results confirm that there is no uniform governance pattern and that the preferred governance form strongly depends on imitability and substitutability in interaction. In the era of incremental change, firms prefer vertical specialization, particularly when substitutability is high. The higher substitutability (lower complexity), the more valuable is flexibility to recombine with new complementary capabilities and the higher (potential) upstream scale advantages. Higher imitability causes lower appropriability so further discourages integration. Transaction costs have a dominant mediating effect on the governance form.

In the era of ferment, governance preferences are more ambiguous. Under high imitability, there is limited appropriability, and firms do not vertically integrate to develop products with superior performance. Nonetheless, firms do then not automatically vertically specialize. After all, under higher complexity (low substitutability), there generally is more incompatibility of component and system such that the combinatorial advantage of vertical specialization decreases, and hence firms are more likely to be vertically integrated.

The findings in this work enhance our understanding of how different industries may have different governance forms in different stages of the product life-cycle, and then particularly in the era of ferment. In this early stage of an industry, firms are unlikely to vertically integrate if technology is highly imitable or highly substitutable, which is for instance the case in low-tech industries with modular components or relatively easily 
separable production steps, e.g. apparel, textiles, and footwear industries. However, even in competitive industries like desktop computers and mobile phones with rather modular technology, there may be instruments like patents to discourage imitation and appropriate the value of innovations. In this case, most firms vertically specialize, yet some firms vertically integrate to develop top performing, integrated products. In industries with systemic products with technologically dedicated components, like the aircraft and lithography equipment industries, there is limited substitutability. In this case, there is vertical integration through research joint ventures.

We also find that the cost structure in up- and downstream industries mediate the governance forms in predictable ways, e.g. strong economies of scale combined with high substitutability in the upstream industry will make downstream firms reluctant to backward integrate.

We have not addressed actual differences in the properties of individual capabilities or changes in these properties. However, as mentioned above, standardization and modularization at industry level will change the substitutability and thereby the propensity to vertically integrate in the early phases of subsequent product life-cycles. Further research should shed light on how changes in the capability regime affect the governance pattern.

We are well aware of the stylized nature and the homogeneity of firm strategies, costs etc. This homogenization allows unambiguously assigning the evolutionary emergence of the governance strategy to properties of the capability regime (and the performance of the strategy itself) rather than other particularities of the firms that we should then also study and report. Moreover, we have 'fixed' the firm behavior and costs before and after the emergence of the dominant design to ensure convergence in the simulation results rather than having to cope with sustained noise and possibly inconclusive simulation results. Further research should shed light on the role of additional strategies in emerging industry evolution and governance patterns.

Moreover, further research is needed to understand governance patterns in product life-cycles with heterogeneous products in which we expect differentiation in the product-market strategies, e.g. vertical integration to horizontally differentiate from competitors. Another interesting extension is to model industries with firms at even more tiers.

Open Access This article is distributed under the terms of the Creative Commons Attribution 4.0 International License (http://creativecommons.org/licenses/by/4.0/), which permits unrestricted use, distribution, and reproduction in any medium, provided you give appropriate credit to the original author(s) and the source, provide a link to the Creative Commons license, and indicate if changes were made.

\section{Appendix 1: Parameter settings}

\section{Technology landscape parameter settings}

We have the following parameter settings to specify the number of capabilities, the number of feasible capability distribution, and the distribution of the capability per- 
formances.

$\begin{array}{rrr}\text { Number of abilities per capability } & N & 6 \\ \text { Number of types of abilities/skills/techniques } & D & 5 \\ \text { Number of feasible capabilities per landscape } & C & 100 \\ \text { Capability performance distribution (scale, tail) } & \alpha, \beta & 3.0,0.5\end{array}$

\section{Parameter settings for macro-economic variables}

We have the following parameter settings in the initialization of and (plotted) macrolevel metrics during the simulation of an industry.

$\begin{array}{rrr}\text { Initial population size } & A & 4 \\ \text { Discounting/expon. smoothing rate capital } & 0.001 \\ \text { Exponential smoothing rate design dominance } & 0.003 \\ \text { othing rate profit margin, market concentration } & 0.01\end{array}$

\section{Strategy parameter settings}

We have the following parameter settings for the decisions that firms take to either explore, imitate or conduct radical innovation

$\begin{array}{rr}\text { Imitation performance threshold (entr./manuf.) } & 1.05,1.15 \\ \text { Min. improvement of top product required (entr./manuf.) } & 0.8,0.9 \\ \text { Required minimum profit threshold to enter (entr./manuf.) } & 0.15,0.05 \\ \text { Maximum design dominance entry (entr./manuf.) } & 0.8,0.8 \\ \text { Radical search profit margin threshold } & 0.02 \\ \text { Radical search dominant design threshold } & 0.90 \\ \text { Business strategy threshold (margin) } & 0.80( \pm 0.06) \\ \text { Strategy imitation failure rate } & 0.05\end{array}$

\section{Demand/diffusion-substitution parameter settings}

We have the following parameter setting to specify the market demand and its development due to substitution-diffusion.

Market size in number of customers

M 4000

Number of customers upon product launch

150

Product panel size

4

Discrete choice choosiness

Q 4

$\gamma \quad 600$ 
Replacement rate $\quad r \quad 0.05$

Standard deviation Rogerian adoption willingness $\quad \mu \quad 30$

Maximum willingness-to-pay $\quad p^{*} \quad 150$

\section{Capital/costs parameter settings}

We have to the following parameter settings to specify the capital the firms have when entering, and the costs that firms make periodically and for certain actions.

Unit production costs (entr./manuf.)

Transaction costs per supplier relation

Periodic manufacturing costs per tier (entr./manuf.)

Capital starting level

Cost of production change (entr./manuf.)

Cost of radical search, imitation of next generation

Cost of governance change (insourcing, outsourcing)
5,2

300

400,850

$800 k$

$0,-50 k$

$-400 k,-200 k$

$-50 k, 0$

\section{Pricing parameter settings}

We have the following parameter settings to specify the polling that firms conduct to adjust their price.

$$
\text { Poll panel size } \quad B \quad 100
$$

Investigated price change $\quad 0.00125$

\section{References}

Afuah A (2000) How much do your co-opetitors' capabilities matter in the face of technological change. Strateg Manag J 21:387-404

Afuah A (2001) Dynamic boundaries of the firm: are firms better off being vertically integrated in the face of a technological change? Acad Manag J 44(6):1211-1228

Anderson P, Tushman M (1990) Technological discontinuities and dominant designs: a cyclical model of technological change. Adm Sci Q 35(4):604-633

Anderson S, de Palma A, Thisse J (1992) Discrete choice theory of product differentiation. MIT Press, London

Argyres N, Bigelow L (2006) Do transaction costs matter at all stages of the industry lifecycle? Technical report

Argyres N, Zenger T (2009) Capabilities, transaction costs, and firm boundaries: a dynamic perspective and integration. Working paper

Argyres N, Bigelow L (2010) Innovation, modularity, and vertical deintegration: evidence from the early U.S. Auto Industry. Organ Sci 21(4):842-853

Balakrishnan S, Wernerfelt B (1986) Technical change, competition and vertical integration. Strateg Manag J 7(4):347-359

Baldwin C, Clark K (2000) Design rules: the power of modularity. MIT Press, London

Barney J (1991) Firm resources and sustained competitive advantage. J Manag 17:99-120

Bass FM (1969) A new product growth model for consumer durables. Manag Sci 15(5):215-227 
Bonaccorsi A, Giuri P (2000) When shakeout doesn't occur: the evolution of the turboprop engine industry. Res Policy 29(7):847-870

Cacciatori E, Jacobides M (2005) The dynamic limits of specialization: vertical integration reconsidered. Organ Stud 26(12):1851-1883

Duysters G (1995) The evolution of complex industrial systems: the dynamics of major IT sectors. Ph.D. thesis, Rijksuniversiteit Limburg, Maastricht

Dyer J, Singh H (1998) The relational view: cooperative strategy and sources of interorganizational competitive advantage. Acad Manag Rev 23(4):660-679

Fagiolo G, Dosi G (2003) Exploitation, exploration and innovation in a model of endogenous growth with locally interacting agents. Struct Change Econ Dyn 14(3):237-273

Fine C (1998) Clockspeed: winning industry control in the age of temporary advantage. Perseus Books, New York

Fisher J, Pry R (1971) A simple substitution model of technological change. Technol Forecast Soc Chang 3:75-88

Gilbert N, Pyka A, Ahrweiler P (2001) Innovation networks: a simulation approach. J Artif Soc Soc Simul 4(3) http://www.soc.surrey.ac.uk/JASSS/4/3/8.html

Gilbert N, Pyka A, Ahrweiler P (2007) Learning in innovation networks: some simulation experiments. Phys A 378:100-109

Hannan M, Freeman J (1977) The population ecology of organizations. Am J Sociol 1982(5):929-964

Harrigan K (1985) Vertical integration and corporate strategy. Acad Manag J 28(2):397-425

Jacobides M, Winter S (2005) The co-evolution of capabilities and transaction costs-explaining the institutional structure of production. Strateg Manag J 26:395-413

Kauffman S (1993) The origins of order: self-organization and selection in evolution. Oxford University Press, Oxford

Klepper S (1996) Entry, exit, growth, and innovation over the product life cycle. Am Econ Rev 86(3):562583

Klepper S (1997) Industry life cycles. Ind Corp Change 6(1):145-182

Kogut B, Zander U (1992) Knowledge of the firm, combinative capabilities, and the replication of technology. Organ Sci 3(3):383-397

Lee C (1958) Some properties of nonbinary error-correcting codes. IRE Trans Inf Theory 4(2):77-82

Leibenstein H (1950) Bandwagon, snob, and veblen effects in the theory of consumers' demand. Q J Econ 64(2):183-207

Levitt T (1965) Exploit the product life cycle. Harv Bus Rev 43:81-94

Malerba F (2006) Innovation and the evolution of industries. J Evol Econ 16:3-23

Marchetti C, Nakicenovic N (1979) The dynamics of energy systems and the logistic substitution model. Research report rr-79-13, International Institute for Applied Systems Analysis, Laxenburg, Austria

McFadden D (1974) Conditional logit analysis of qualitative choice behavior. In: Zarembka P (ed) Frontiers in econometrics. Academic Press, New York, pp 105-142

Murmann J, Frenken K (2006) Toward a systematic framework for research on dominant designs, technological innovations, and industrial change. Res Policy 35:925-952

Nelson RR, Winter SG (1982) An evolutionary theory of economic change. Harvard University Press, Cambridge

Norton JA, Bass FM (1987) A diffusion theory model of adoption and substitution for successive generations of high-technology products. Manag Sci 33(9):1069-1086

Prahalad C, Hamel G (1990) The core competence of the corporation. Harvard Business Review, Watertown

Pyka A, Gilbert N, Ahrweiler P (2009) Agent-based modelling of innovation networks - the fairytale of spillover. In: Pyka A, Scharnhorst A (eds) Innovation networks, understanding complex systems. Springer, Berlin, pp 101-126

Rogers E (1995) Diffusion of innovations, 4th edn. The Free Press, New York

Sanchez R, Mahoney J (1996) Modularity, flexibility, and knowledge management in product and organization design. Strateg Manag J 17:63-76

Schilling M (2000) Toward a general modular systems theory and its application to interfirm product modularity. Acad Manag Rev 25(2):312-334

Schilling M, Steensma H (2001) The use of modular organizational forms: an industry-level analysis. Acad Manag J 44(6):1149-1168 
Silverberg G, Verspagen B (2003) Empirics and abstraction in the analysis of innovation: the size distribution of innovations. Paper prepared for the conference 'What do we know about innovation?' In honour of Keith Pavitt, Brighton, November 13-15, 2003

Smith A (2003) The Wealth of Nations (1776). Bantam Classics

Stigler G (1951) The division of labor is limited by the extent of the market. J Polit Econ 59(3):185-193

Sweeney J, Soutar G (2001) Consumer perceived value: the development of a multiple item scale. J Retail 77:203220

Teece D, Pisano G, Shuen A (1997) Dynamic capabilities and strategic management. Strateg Manag J 18(7):509-533

Train K (2002) Discrete choice methods with simulation. Cambridge University Press, Cambridge

Tushman M, Anderson P (1986) Technological discontinuities and organizational environments. Adm Sci Q 31(3):439-465

Utterback J, Abernathy W (1975) A dynamic model of process and product innovation. Omega 3(6):639-656

Wasson C (1974) Dynamic competitive strategy and product life cycles. Challenge Books, St. Charles

Williamson O (1981) The economics of organization: the transaction cost approach. Am J Sociol 87(3):548577

Williamson O (1985) The economic institutions of capitalism: firms, markets, relational contracting. The Free Press, New York

Windrum P, Birchenhall C (1998) Is product life cycle theory a special case? Dominant designs and the emergence of market niches through coevolutionary learning. Struct Change Econ Dyn 9(1):109-134 